\title{
Activatable Second Near-Infrared Fluorescent Probes: A New Accurate Diagnosis Strategy for Diseases
}

\author{
Dong Li ${ }^{*}{ }^{\dagger}$, Jie Pan ${ }^{\dagger}$, Shuyu Xu, Shiying Fu (D, Chengchao Chu and Gang Liu *(1) \\ State Key Laboratory of Molecular Vaccinology and Molecular Diagnostics, Center for Molecular Imaging, \\ Translational Medicine School of Public Health, Xiamen University, Xiamen 361102, China; \\ 32620201150737@stu.xmu.edu.cn (J.P.); xushuyu@stu.xmu.edu.cn (S.X.); 21620191152631@stu.xmu.edu.cn (S.F.); \\ chuchengchao@xmu.edu.cn (C.C.) \\ * Correspondence: lidong@xmu.edu.cn (D.L.); gangliu.cmitm@xmu.edu.cn (G.L.) \\ + These authors contributed equally to this work.
}

check for updates

Citation: Li, D.; Pan, J.; Xu, S.; Fu, S.; Chu, C.; Liu, G. Activatable Second Near-Infrared Fluorescent Probes: A New Accurate Diagnosis Strategy for Diseases. Biosensors 2021, 11, 436. https://doi.org/10.3390/bios11110436

Received: 9 October 2021

Accepted: 29 October 2021

Published: 2 November 2021

Publisher's Note: MDPI stays neutral with regard to jurisdictional claims in published maps and institutional affiliations.

Copyright: (c) 2021 by the authors. Licensee MDPI, Basel, Switzerland. This article is an open access article distributed under the terms and conditions of the Creative Commons Attribution (CC BY) license (https:/ / creativecommons.org/licenses/by/ $4.0 /)$.

\begin{abstract}
Recently, second near-infrared (NIR-II) fluorescent imaging has been widely applied in biomedical diagnosis, due to its high spatiotemporal resolution and deep tissue penetration. In contrast to the "always on" NIR-II fluorescent probes, the activatable NIR-II fluorescent probes have specific targeting to biological tissues, showing a higher imaging signal-to-background ratio and a lower detection limit. Therefore, it is of great significance to utilize disease-associated endogenous stimuli (such as $\mathrm{pH}$ values, enzyme existence, hypoxia condition and so on) to activate the NIRII probes and achieve switchable fluorescent signals for specific deep bioimaging. This review introduces recent strategies and mechanisms for activatable NIR-II fluorescent probes and their applications in biosensing and bioimaging. Moreover, the potential challenges and perspectives of activatable NIR-II fluorescent probes are also discussed.
\end{abstract}

Keywords: NIR-II fluorescent probes; activatable strategy; NIR-II fluorescence imaging; biomarker; biosensing

\section{Introduction}

Fluorescence imaging techniques are widely used in the fields of disease detection and diagnosis, surgical navigation, and drug delivery, due to their high sensitivity and noninvasiveness, and the absence of ionizing radiation [1-3]. According to different emission wavelengths, fluorescence imaging can be divided into three regions: the visible region (400-700 $\mathrm{nm}$ ), the first near-infrared region (NIR-I, 700-900 nm), and the second near-infrared region (NIR-II, 1000-1700 nm) [4-6]. In comparison with NIR-I fluorescence imaging, NIR-II fluorescence imaging has the characteristics of less scattering, minimal tissue absorption, and low autofluorescence, which can produce deeper tissue penetration and a higher signal-to-background ratio (SBR) [7-9]. To date, varieties of NIR-II fluorescent probes, including benzobisthiadiazole (BBTD) dyes, semiconducting polymer nanoparticles (SPNPs), cyanine dyes, quantum dots (QDs), and single-wall carbon nanotubes (SWCNTs) have been developed for applications in NIR-II fluorescence imaging [10-12].

Recently, accurate in vivo diagnosis based on specific biomarkers produced by diseases has attracted extensive attention $[13,14]$. Specifically, the pathological microenvironment of diseased tissue is obviously different from that of normal tissue, and the occurrence and development of many diseases produce specific biomarkers [15-17]. For example, the $\mathrm{pH}$ value and the reactive oxygen species (ROS) concentration are abnormal in the tumor microenvironment [18-20], hepatotoxicity induced by drugs has an abnormal ONOOconcentration [21], and liver injury induced by diabetes leads to viscosity changes [22]. Encouragingly, the specific biomarkers generated by the disease can be exploited to activate NIR-II fluorescence probes, realizing the accurate diagnosis of the underlying disease [23]. Compared with the "always on" types of NIR-II fluorescent probes, activatable NIR-II 
fluorescent probes can be specifically recognized by the target tissue and exhibit switchable fluorescence emission $[13,14]$. In fact, activatable NIR-II fluorescent probes cannot produce fluorescence, or produce only weak fluorescence; however, the special structure reacts with certain molecules existing in the microenvironment of the diseased tissue, thereby producing effective NIR-II fluorescence emission [24-26]. Consequently, the "off" state in normal tissues and the "on" state in the diseased tissues can significantly improve the sensitivity and resolution of the fluorescence imaging [27-29]. Therefore, it is of great significance to utilize disease-associated endogenous stimuli to specifically activate NIR-II fluorescent probes for highly sensitive and high-resolution bioimaging.

Activatable NIR-II fluorescent probes (e.g., small organic molecular fluorophores, inorganic nanoparticles, and semiconducting polymer nanoparticles) for specific fluorescence imaging have made rapid progress. Here, recent strategies for activatable NIR-II fluorescent probes and their applications in biosensing and bioimaging are summarized (Scheme 1). In addition, according to the characteristics of highly expressed biomarkers in diseases, the activation mechanism is comprehensively analyzed and discussed. Finally, the prospects are also analyzed.

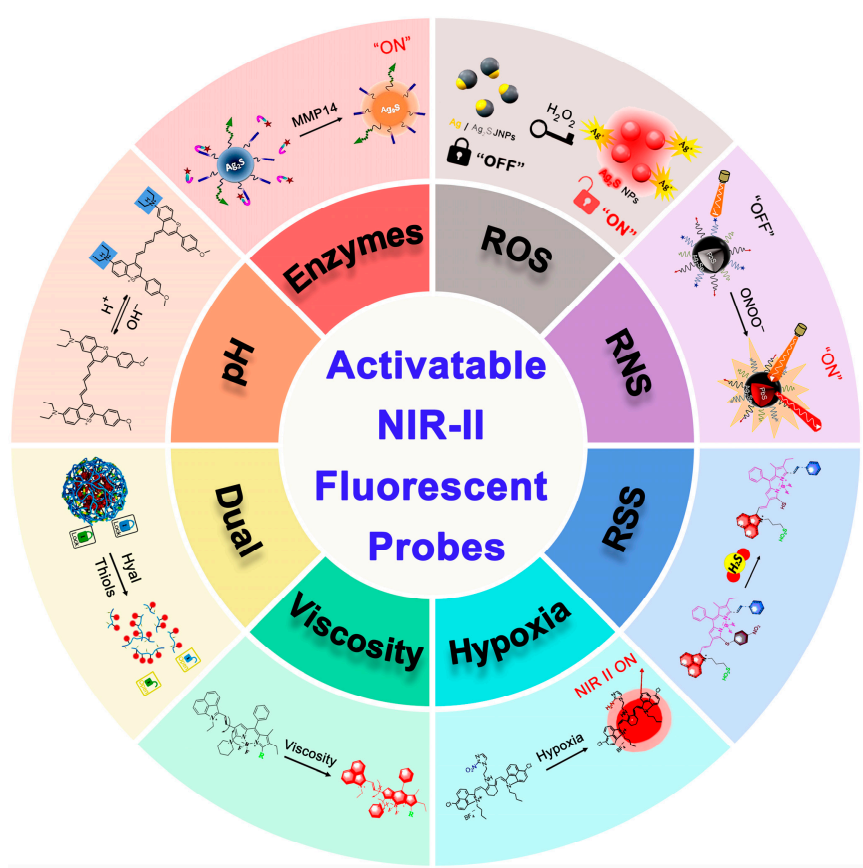

ROS: Reactive Oxygen Species RNS: Reactive Nitrogen Species RSS: Reactive Sulfur Species

Scheme 1. Schematic illustration of strategies and mechanisms for activatable NIR-II fluorescent probes. Image for $\mathrm{pH}$ : reproduced from publication of Wang, S. et al. with permission, Copyright 2019, Nature Publishing Group. Image for enzymes: reproduced from publication of Zhan, Y. et al. with permission, Copyright 2021, WILEY-VCH. Image for ROS: reproduced from publication of Zhang, X. et al. with permission, Copyright 2021, American Chemical Society. Image for RNS: reproduced from publication of Yang, X. et al. with permission, Copyright 2021, WILEY-VCH. Image for RSS: reproduced from publication of Dou, K. et al. with permission, Copyright 2021, American Chemical Society. Image for hypoxia: reproduced from publication of Meng, X. et al. with permission, Copyright 2018, Creative Commons. Image for viscosity: reproduced from publication of Dou, K. et al. with permission, Copyright 2021, American Chemical Society. Image for dual: reproduced from publication of Tang, Y. et al. with permission, Copyright 2018, WILEY-VCH. 


\section{NIR-II Fluorescent Probes}

\subsection{Organic NIR-II Fluorescent Probes}

Organic NIR-II fluorescent probes are applied in biological imaging for disease diagnosis, and mainly include BBTD dyes, aggregation-induced emission luminogens (AIEgens), SPNPs, cyanine dyes, rhodamine analogs, and boron dipyrromethenes (BODIPYs), with representative structures CH1055, TQ-BPN, poly (benzo [1,2-b:3,4-b'] difuranalt-fluorothieno-[3,4-b] thiophene) (pDA), FD-1080, RhIndz, and NJ1060, respectively (Figure 1) [30,31]. Specifically, BBTD derivatives exhibit donor-acceptor-donor (D-A-D) characteristics with large Stokes shifts and high imaging quality [32]. In 2016, Antaris et al. reported the BBTD core structure CH1055 with fluorescence emission at $1055 \mathrm{~nm}$, which outperformed the clinically used indocyanine green (ICG) for sentinel lymphatic imaging in the vicinity of mouse tumors [2]. In addition, a high enrichment of PEGylated CH1055 dye was observed in the deep tissues of mouse brain tumors at approximately $4 \mathrm{~mm}$. Moreover, the tumor-to-normal tissue ratio of NIR-II imaging mediated by the CH1055 dye was 5 times higher than that of NIR-I imaging, enabling it to be used for in vivo imaging to guide tumor resection. In 2019, Zhou et al. developed two NIR-II fluorescent probes, CH1055-PEG-PT and CH1055-PEG-Affibody, which showed great potential in the fluorescence imaging of osteosarcoma and lung metastasis, respectively. In addition, CH1055-PEG-PT surpassed the imaging capability of computed tomography for a 143B tumor in vivo, and could therefore be used to guide surgical resection of $143 \mathrm{~B}$ tumors. CH1055-PEG-Affibody could be used to visualize osteosarcoma and lung metastasis [33]. In contrast to the traditional supramolecular dyes, AIE molecules overcame the aggregation-caused quenching (ACQ) induced by intermolecular $\pi-\pi$ stacking. Qi et al. reported a crab-shaped AIEgen, TQ-BPN, with fluorescence emission at 700-1200 nm for high-resolution microangiography and imaging in the NIR-II window [34]. The excellent imaging performance of TQ-BPN ensured visualization of the anatomy of high-depth brain capillaries $(800 \mu \mathrm{m})$ with high spatial resolution $(\sim 3 \mu \mathrm{m})$. Therefore, TQ-BPN could be used to dynamically evaluate vascular diseases for the diagnosis of blood-brain barrier damage in the brain. Samanta et al. developed a highly bright, highly water-soluble aggregation-induced emission (AIE)-active two-photon (TP) (AIETP) NIR-II probe, which could form hydrophilic nanoparticles, AIETP NPs, with the polymer Pluronic F127. Encouragingly, AIETP NPs not only exhibited excellent cell permeability and biocompatibility but also exhibited good two-photon imaging properties in vivo. Moreover, due to the superior penetration depth $(800 \mu \mathrm{m})$ and excellent spatial resolution $(1.92 \mu \mathrm{m})$, AIETP NPs were applied to deep brain imaging in vivo [35]. SPNPs are organic semiconducting macromolecules whose backbone consists of alternating single and double bonds. Among these, pDA is a typical SPNP, with an emission wavelength of $1050 \mathrm{~nm}$ and a Stokes shift of approximately $400 \mathrm{~nm}$, which can be used for vascular imaging in vivo [5]. Importantly, pDA has a frame rate of $>25$ frames per second, which can be applied to deep tissue and ultrafast imaging of mouse arterial blood flow. Cyanine dyes are based on a polymethylene skeleton and contain a unique extended conjugated system. Specifically, FD-1080 is a polymethine cyanine dye with an emission wavelength of $1080 \mathrm{~nm}$, which can achieve noninvasive high-resolution angiography of deep-tissue brain and hindlimb vessels [36]. In addition to the abovementioned typical dyes, traditional NIR-I dyes modified with specific groups can achieve NIR-II fluorescence emission. RhIndz and NJ1060 are derivatives of rhodamine and BODIPY, respectively $[37,38]$. With the modification of special functional groups, both RhIndz and NJ1060 achieved NIR-II fluorescence emission. It is worth noting that organic NIR-II fluorescent probes show great potential in the application of surgical navigation. Zeng et al. designed a small-molecule fluorescent probe, H3-PEG2k, with excellent aqueous solubility, high brightness, and high photostability [39]. When H3-PEG2k was intravenously injected into rats with mammary carcinoma, a strong fluorescence signal could be observed within $8 \mathrm{~h}$ after injection. In addition, the tumor and the surrounding normal tissues could be clearly distinguished $8.5 \mathrm{~h}$ after injection. Encouragingly, H3-PEG2k was applied to rat mammary carcinoma imaging as well as image-guided 
tumor resection surgery. This research provided important guidance for the use of NIR-II fluorescence probes in clinical breast cancer imaging in vivo and in surgical navigation.

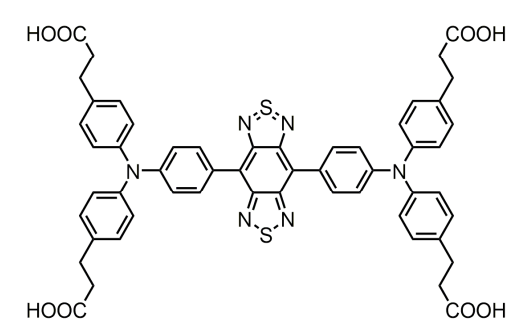

$\mathrm{CH} 1055$

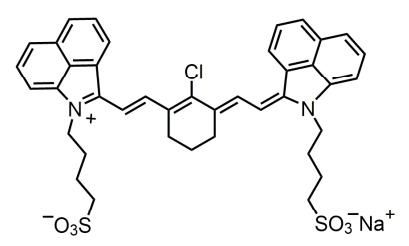

FD-1080

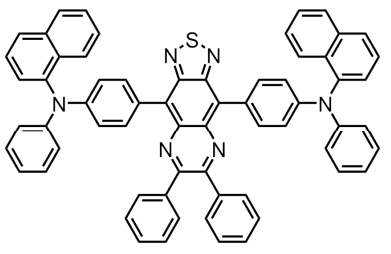

TQ-BNP

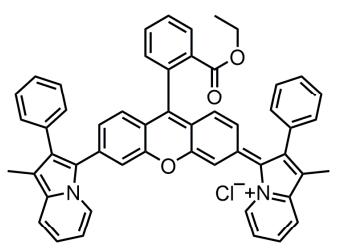

Rhlndz

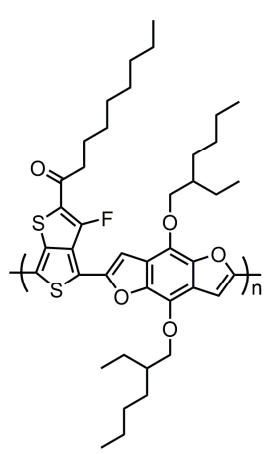

pDA

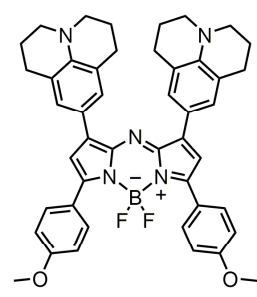

NJ1060

Figure 1. Chemical structures of CH1055, TQ-BNP, pDA, FD-1080, Rhlndz, and NJ1060.

\subsection{Inorganic NIR-II Fluorophores}

Compared with organic NIR-II fluorescent probes, inorganic NIR-II fluorescent probes, including QDs, SWCNTs, and rare-earth-doped nanoparticles (RENPs) have excellent quantum yield and high stability $[40,41]$. Among the multiple NIR-II fluorescent probes reported thus far, QDs have attracted much attention due to their excellent fluorescence quantum yield [42]. Recently, a series of metal-sulfur QDs have been reported to possess excellent NIR-II fluorescence properties, including $\mathrm{Ag}_{2} \mathrm{~S}, \mathrm{PbS}$, and $\mathrm{ZnS}$ [32]. Specifically, $\mathrm{Ag}_{2} \mathrm{~S}$ QDs are widely used in preclinical research due to the excellent tunability of their optical properties, their excellent biocompatibility, and their low cytotoxicity. The NIR-II fluorescence imaging of $\mathrm{Ag}_{2} \mathrm{~S}$ QDs has high spatial resolution $(\sim 40 \mu \mathrm{m})$ and can track angiogenesis mediated by tumors ( $2-3 \mathrm{~mm}$ in diameter) in vivo [43]. On the other hand, due to their narrow band gap, SWCNTs can generate a fluorescence emission spectrum with wavelengths from $1000 \mathrm{~nm}$ to $1800 \mathrm{~nm}$, which can be used for in vivo NIR-II fluorescence imaging of tumor vessels in deep tissues [44]. Ghosh et al. reported a SWCNT modified with a SPARC binding peptide (SBP) and M13 phage, which can be used for the detection of tumor nodules on multiple abdominal viscera and the mesentery [45]. With the NIR-II fluorescence reflectance imaging system, SBP-M13-SWNT-mediated fluorescence imaging can detect tumors at a depth of 9.7-18.2 mm. Notably, compared with the fluorescent probes fluorescein isothiocyanate (FITC) and AlexaFluor750 dye (AF750), the tumor-tomuscle ratio of SBP-M13-SWNT was $5.5 \pm 1.2$, which was significantly higher than that of SBP-M13-FITC $(0.96 \pm 0.10)$ or SBP-M13-AF750 (3.1 \pm 0.42$)$. RENPs were also applied in NIR-II fluorescence imaging where rare earth (RE) metals were embedded in an inorganic crystalline host matrix (for example, $\mathrm{NaYF}_{4}$ or $\mathrm{CaF}_{2}$ ). In addition, RENPs possess an adjustable emission spectrum, long luminescence life and good photostability; hence, they are expected to replace traditional organic fluorescent materials for fluorescence imaging [7]. Lei et al. doped cerium ions $\left(\mathrm{Ce}^{3+}\right)$ into the $\mathrm{NaYbF}_{4}: \mathrm{Er}^{3+}$ nanostructure and achieved fluorescence emission at $1550 \mathrm{~nm}$ [46], and further in vivo experiments showed that $\mathrm{NaCeF}_{4}: \mathrm{Er} / \mathrm{Yb}$ could be used for deep-tissue NIR-II fluorescence imaging of mouse 
hind limbs. Xue et al. developed polyacrylic acid (PAA)-modified $\mathrm{NaYF}_{4}: \mathrm{Gd} / \mathrm{Yb} / \mathrm{Er}$ nanorods (PAA-NRs), which could be used for the visual detection of microscopic tumors via NIR-II fluorescence imaging. Notably, non-invasive high-resolution and highly spatial (down to $43.65 \mu \mathrm{m}$ ) NIR-II brain vasculature imaging was achieved using PAA-NRs [47]. In summary, a wide variety of NIR-II fluorescent probes have been prepared and have shown great potential in tumor imaging, deep-seated disease detection, surgical navigation, and therapeutic effect evaluation.

\section{Activatable NIR-II Fluorescent Probes}

Although NIR-II fluorescent probes have excellent optical properties for bioimaging, the "always on" fluorescent probes produce nonspecific signals in normal tissues, reducing the detection sensitivity [48]. In comparison with the "always on" fluorescent probes, activatable fluorescent probes achieve high specificity by increasing the target signal intensity and reducing the background signal [49]. According to the activation modes, these strategies mainly include eight categories: $\mathrm{pH}$, enzymes, ROS, reactive nitrogen species (RNS), reactive sulfur species (RSS), hypoxia, viscosity and dual-responsive.

\section{1. $p H$}

$\mathrm{pH}$ plays an important role in the physiological homeostasis of the living body [50,51] Abnormal $\mathrm{pH}$ values affect the physiological balance, which is related to the occurrence and development of a variety of diseases [13,52]. For example, the $\mathrm{pH}$ value in gastric juice can affect the activity of digestive enzymes in gastric juice and the utilization of oral drugs [53]. The $\mathrm{pH}$ value in gastric juice can be monitored using a $\mathrm{pH}$-sensing fluorescent probe. In 2019, Wang et al. reported a benzothiopyrylium pentamethine cyanine substituted by diethylamino (BTC1070) probe with high-penetration NIR-II imaging properties, which exhibited superior $\mathrm{pH}$-responsive properties (Figure 2a) [54]. Interestingly, when the $\mathrm{pH}$ value was reduced from 5 to 2, the maximum absorption peak at $1015 \mathrm{~nm}$ decreased and a new absorption peak at 600-900 nm appeared (Figure 2b). The values of pKa were 0.29 and 3.81 by Boltzmann curve fitting, which clearly indicated that BTC1070 had a double protonation feature. The protonation process led to the inhibition of the intramolecular charge transfer (ICT) effect, which realized the fluorescence response ratio (Figure 2c). In addition, mice were treated with simulated gastric juice of $\mathrm{pH} 1.3$ or 2.5 to simulate the acidic environment of the human stomach. The fluorescence imaging of BTC1070 in gastric juices at different $\mathrm{pH}$ values was monitored by noninvasive ratiometric imaging at different tissue depths, and the results indicated that BTC1070 could be used for highcontrast fluorescence imaging of deep tissues, to noninvasively detect the $\mathrm{pH}$ value in gastric juice (Figure 2d). Overall, this investigation showed that pentamethine fluorophore could be used in $\mathrm{pH}$-activated NIR-II fluorescence imaging for accurate detection of $\mathrm{pH}$ in gastric juice.

Cancer is a heterogeneous disease which differs from normal tissue in morphology and growth mode [55-57]. The rapid proliferation of tumor cells leads to the characteristic changes in energy metabolism [58,59]. Tumor cells are vigorous with respect to energy metabolism, consuming large amounts of glucose and converting it to lactate, resulting in an increase in extracellular $\mathrm{H}^{+}$concentration and a decrease in $\mathrm{pH}$ value $[18,60,61]$. Inorganic NIR-II fluorescent probes have a high degree of stability, which can be controlled by modifying the pH-responsive groups on their surfaces. In 2020, Ling et al. reported a NIR-II nanodrug system (FEAD1) for precise tumor theranostics via tumor acid activation, which was self-assembled by the Fmoc-His peptide, mercaptopropionic-modified $\operatorname{Ag}_{2} \mathrm{~S}$ QDs (MPA-Ag ${ }_{2} \mathrm{~S}$ QDs), NIR absorber A1094, and doxorubicin (DOX) [62]. The NIRII fluorescence of FEAD1 was largely quenched, due to the Forster resonance energy transfer (FRET) between $\mathrm{Ag}_{2} \mathrm{~S}$ QDs and A1094. However, under the acidic conditions of the tumor, the disassembly of FEAD1 by protonation of the imidazole groups led to a loss of FRET, enabling NIR-II fluorescence recovery. In vivo experiments showed that FEAD1 not only formed specific NIR-II fluorescence signals in the breast cancer sites 
of mice but also illuminated peritoneal metastatic tumor nodules over a long period, endowing this novel $\mathrm{pH}$-activatable NIR-II fluorescent probe with excellent potential for clinical applications. In 2021, Liu et al. reported novel $\mathrm{pH}$-sensitive nanovesicles assembled by thiolated polystyrene-co-poly(4-vinylpyridine)-modified $\mathrm{Ag}_{2} \mathrm{~S}$ QDs $\left(\mathrm{Ag}_{2} \mathrm{~S}\right.$ Ve) for precisely activating NIR-II fluorescence imaging (Figure 2e) [63]. The pyridine group of 4-vinylpyridine was easily protonated at a lower $\mathrm{pH}$ value, demonstrating that $\mathrm{Ag}_{2} \mathrm{~S}$ Ve had the capacity for $\mathrm{pH}$ responsiveness. As shown in Figure $2 \mathrm{f}$, under acidic conditions the fluorescence intensity of $\mathrm{Ag}_{2} \mathrm{~S}$ Ve gradually recovered in the range of 1000 to $1400 \mathrm{~nm}$ within $90 \mathrm{~min}$. In vivo NIR-II fluorescence imaging indicated that $\mathrm{Ag}_{2} \mathrm{~S}$ Ve showed obvious fluorescence in the tumor site at 12 and $24 \mathrm{~h}$, while the control group showed no fluorescence, demonstrating excellent $\mathrm{pH}$-responsive properties (Figure $2 \mathrm{~g}$ ).

a

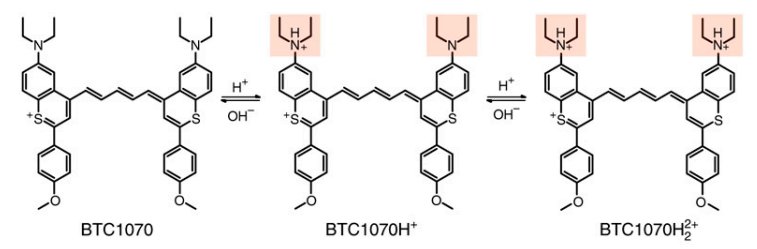

b

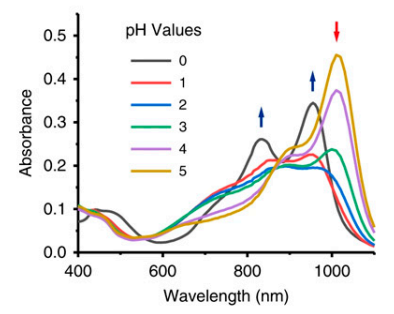

C

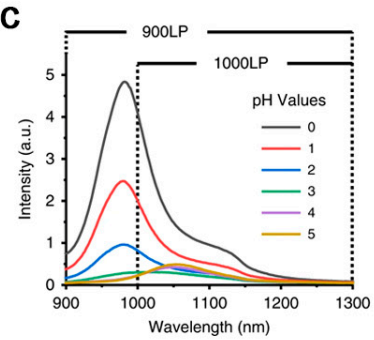

e

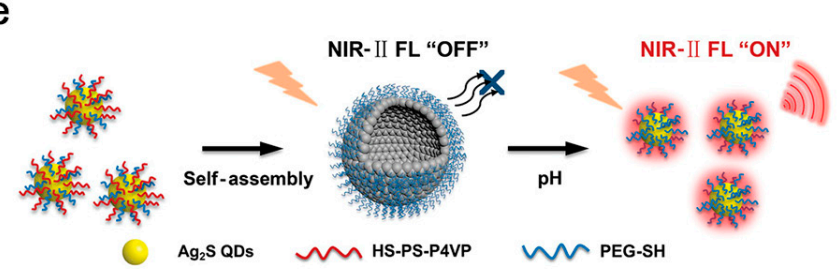

$\mathrm{Ag}_{2} \mathrm{~S}$ QDS WS-PS-P4VP W PEG-SH

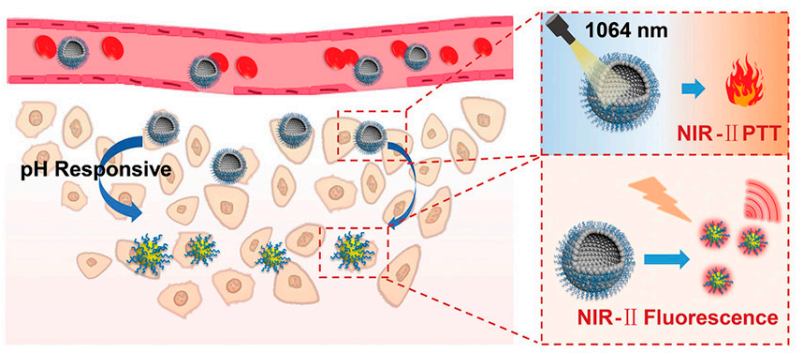

d

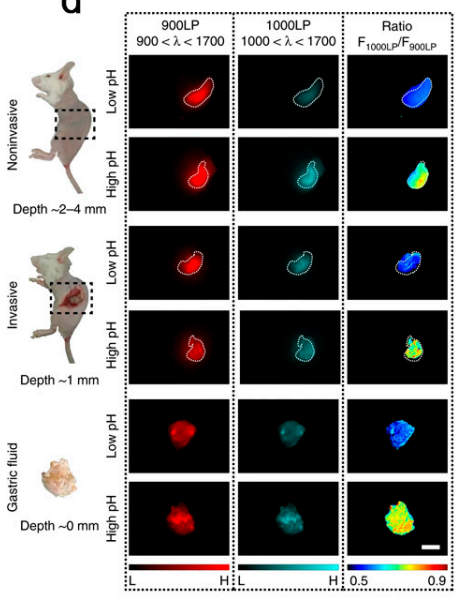

f
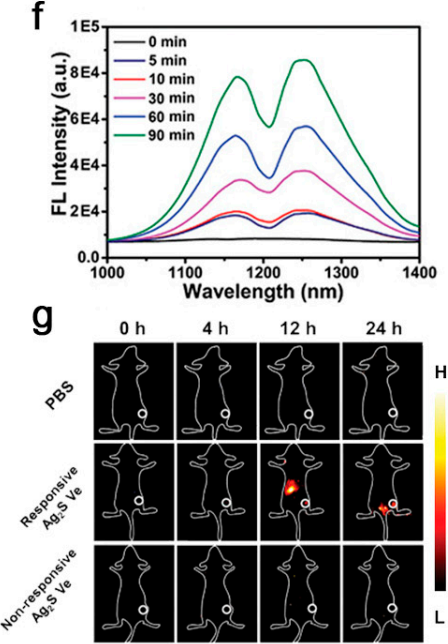

Figure 2. (a) Chemical structure of BTC1070 and its protonation mechanism. (b) Electronic absorption and (c) fluorescence spectra of BTC1070 in PBS at different $\mathrm{pH}$ conditions (excited at $808 \mathrm{~nm}$ ). (d) Digital photographs of three imaging modes distinguished based on different tissue depths (left) and fluorescence imaging and ratiometric fluorescence imaging of BTC1070 in gastric juice at different $\mathrm{pH}$ under three imaging modes (right). Reproduced with permission [54]. Copyright 2019, Nature Publishing Group. (e) Schematic diagram of self-assembly process of $\mathrm{Ag}_{2} \mathrm{~S}$ QDs into $\mathrm{pH}$-activatable $\mathrm{Ag}_{2} \mathrm{~S}$ Ve and the mechanism of $\mathrm{pH}$-activatable $\mathrm{Ag}_{2} \mathrm{~S}$ Ve for NIR-II fluorescenceimaging-guided photothermal cancer therapy in vivo. (f) Fluorescence spectra of $\mathrm{pH}$-activatable $\mathrm{Ag}_{2} \mathrm{~S}$ Ve triggered by low $\mathrm{pH}$ condition at different time points under the irradiation of $808 \mathrm{~nm}$ laser. (g) Time-dependent NIR-II fluorescence imaging of tumors in vivo after treatment with PBS and $\mathrm{pH}$-activatable and non-activatable $\mathrm{Ag}_{2} \mathrm{~S}$ Ve $(10 \mathrm{mg} / \mathrm{mL})$. Reproduced with permission [63]. Copyright 2021, WILEY-VCH. 


\subsection{Enzymes}

Enzymes are an extremely important class of biocatalysts which are involved in a great number of biological reactions in living organisms, and abnormalities in their concentrations are often associated with the development of various diseases [64-66]. For example, $\beta$-galactosidase ( $\beta$-Gal), an enzyme that can hydrolyze substances containing a $\beta$-glycoside bond, exists widely in living organisms $[67,68]$. An increase in the content of $\beta$-Gal in the human body usually induces the occurrence of ovarian cancer, and sensitive detection of $\beta-\mathrm{Gal}$ is therefore important for the early prediction and diagnosis of ovarian cancer [69-71]. Chen et al. developed an activatable galactose-modified BODIPY BODM- $\beta$ Gal NIR-II fluorescent probe (Figure 3a) [72]. The transition of BODIPY from NIR-I to NIR-II was achieved by providing elongation of the $\pi$-conjugation to BODIPY via a vinylene unit. As shown in Figure $3 \mathrm{~b}, \beta$-Gal enhanced the fluorescence of BOD-M- $\beta$ Gal significantly within $20 \mathrm{~min}$, showing enzyme-responsive fluorescence emission in the NIR-II region. In vivo fluorescence imaging indicated that BOD-M- $\beta$ Gal achieved excellent imaging of tumor regions, while the additional inhibitor D-galactose significantly inhibited the fluorescence intensity, showing the specificity of the enzyme response (Figure 3c). Moreover, at a depth of $2 \mathrm{~mm}$, the bright NIR-II signal of BOD-M- $\beta$ Gal could be observed, while the NIR-I fluorescence signal was barely detected (Figure 3d).

Matrix metalloproteinase (MMP) is a type of matrix-degrading enzyme which plays an important role in atherosclerosis, rheumatoid arthritis, enteritis, cancer, and other inflammatory diseases [73-75]. Jeong et al. reported a protease-activatable QD (PA-NIR QD) NIR-II probe, which was obtained by combining a PbS/CdS/ZnS multishell fluorescent probe with activatable modulators (AcMs) [76]. When PA-NIR QD was loaded with the photosensitizer methylene blue (MB), the PA-NIR QD was quenched by photoinduced electron transfer (PET) and was activated specifically in the presence of MMP. After simultaneous incubation of MMP2 with PA-NIR QD, the fluorescence recovery efficiency of PA-NIR QD increased with an increase in MMP2. Furthermore, when the PA-NIR QD was injected in a tumor mouse model, the tumor area showed a stronger fluorescence signal than the normal tissue, indicating that MMP-activated PA-NIR QD achieved real-time, high-resolution fluorescence imaging. Recently, Zhan et al. reported the NIR-II fluorescent probe A\&MMP@ $\mathrm{Ag}_{2} \mathrm{~S}-\mathrm{AF7P}$, specifically activated by the MMP14 enzyme for rapid diagnosis of neuroblastoma (NB) (Figure 3e) [77]. A\&MMP@ $\mathrm{Ag}_{2} \mathrm{~S}-\mathrm{AF7P}$ is modified by the MMP14-targeting peptide AF7P, polycationic peptide R9 and poly-anionic fragments E8, which are taken up by NB cells overexpressing MMP14, and FRET is disrupted, resulting in rapid activation of NIR-II fluorescence. As shown in Figure 3f, the extra MMP14 recovered the fluorescence of A\&MMP@Ag 2 S-AF7P, and the fluorescent probe was lit up within $45 \mathrm{~min}$, indicating that this enzymatic reaction was fast and efficient. In vitro and ex vivo experiments showed that A\&MMP@ $\mathrm{Ag}_{2} \mathrm{~S}-\mathrm{AF7P}$ could be activated by MMP14 to produce obvious NIR-II fluorescence signals (Figure $3 \mathrm{~g}, \mathrm{~h}$ ). 
a

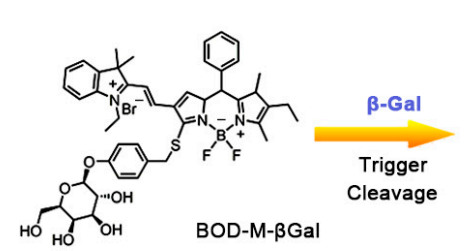

b

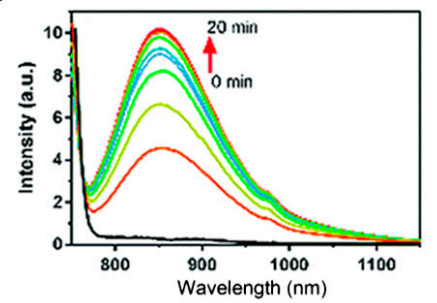

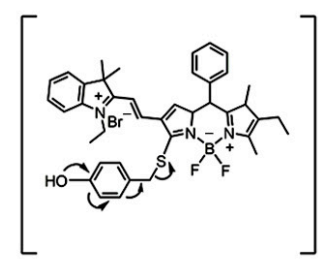

C

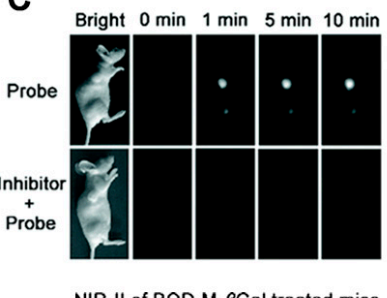

NIR-II of BOD-M- $\beta$ Gal treated mice

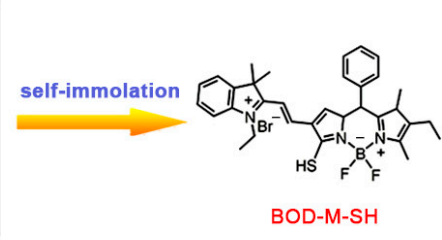

d

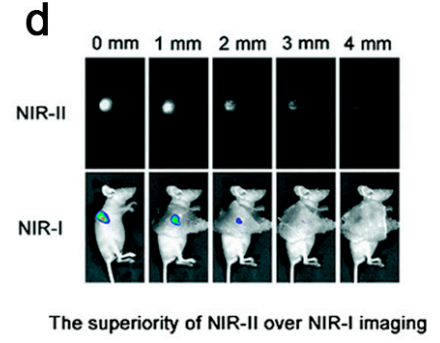

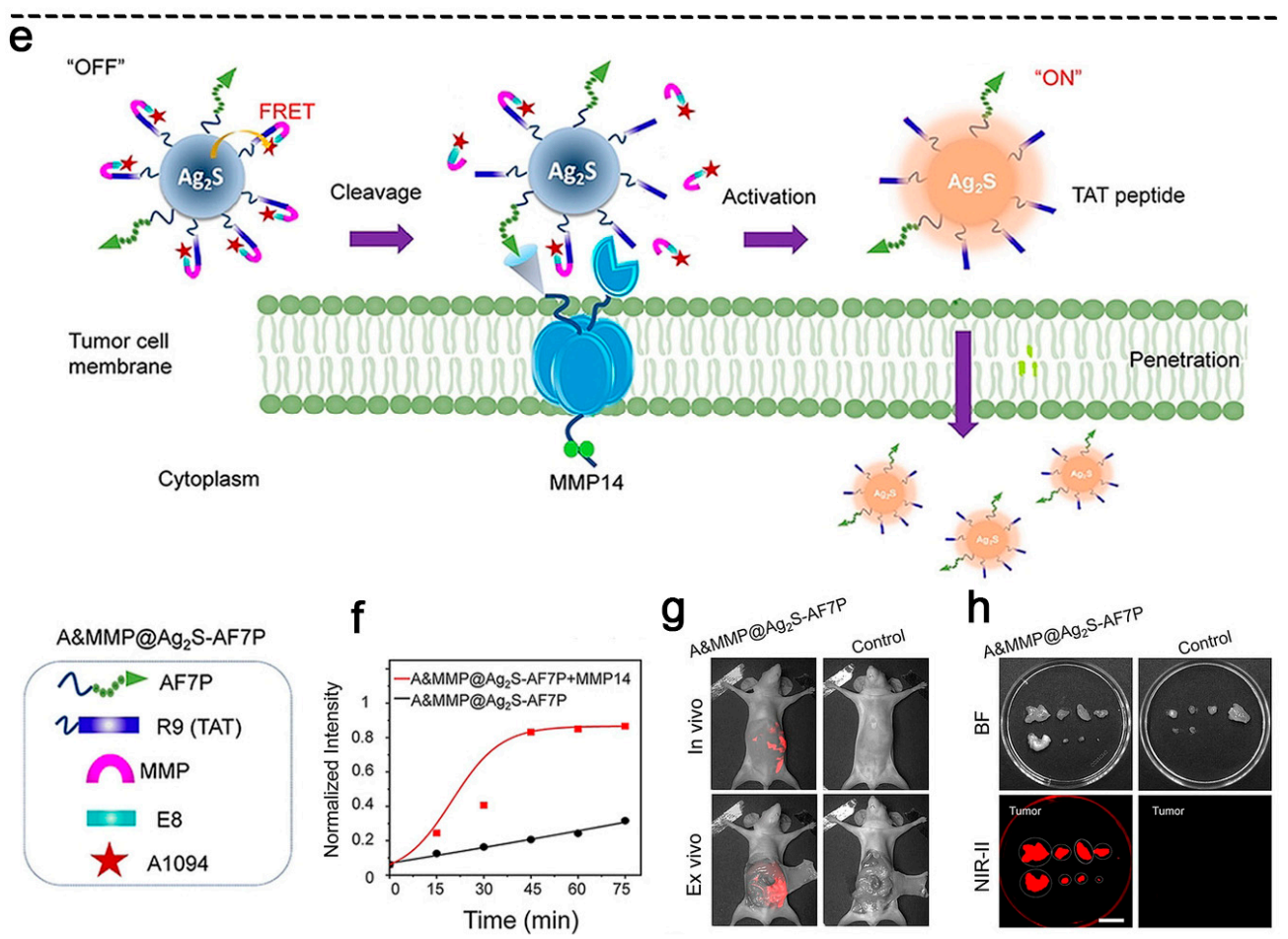

Figure 3. (a) Schematic illustration of the mechanism for $\beta$-Gal enzymatic activation process of BOD-M- $\beta$ Gal. (b) Time-dependent NIR-II fluorescence spectra of BOD-M- $\beta$ Gal upon addition of $\beta$-Gal in mixed aqueous solution. (c) NIR-II fluorescence imaging of mice at different time points after treatment with BOD-M- $\beta$ Gal and BOD-M- $\beta$ Gal + inhibitor D-galactose. (d) Comparison of NIR-II and NIR-I fluorescence imaging of mice after treatment with BOD-K- $\beta$ Gal and BOD-M- $\beta$ Gal in various deep-tissue environments. Reproduced with permission [72]. Copyright 2020, Royal Society of Chemistry. (e) Schematic diagram of A\&MMP@Ag ${ }_{2} \mathrm{~S}-\mathrm{AF7P}$ for NB detection. (f) Validation of MMP14-mediated fluorescence recovery of A\&MMP@Ag 2 S-AF7P. (g) NIR-II fluorescence and bright field $(\mathrm{BF})$ imaging of peritoneal tumors in vivo and ex vivo after intraperitoneal injection of A\&MMP@Ag 2 S-AF7P. (h) BF and NIR-II fluorescence imaging of resected tumor nodules (scale bar $=5 \mathrm{~mm}$ ). Reproduced with permission [77]. Copyright 2021, WILEY-VCH.

\section{3. $R O S$}

ROS, mainly including hydrogen peroxide $\left(\mathrm{H}_{2} \mathrm{O}_{2}\right)$, superoxide anion $\left(\mathrm{O}_{2}{ }^{\bullet-}\right)$, hypochlorite $\left(\mathrm{ClO}^{-}\right)$, and hydroxyl radicals $(\cdot \mathrm{OH})$, can affect many physiological and pathological processes, such as cell apoptosis, cell signal transduction, and cancer [78-80]. Some investigations have shown that the $\mathrm{H}_{2} \mathrm{O}_{2}$ concentration in tumor tissue or at inflammatory sites was much higher than that in normal tissue [18,81]. In 2021, Zhang et al. reported a 
size-tunable $\mathrm{Ag} / \mathrm{Ag}_{2} \mathrm{~S}$ Janus NP (JNP) NIR-II fluorescent nanoprobe activated by endogenous $\mathrm{H}_{2} \mathrm{O}_{2}$ (Figure 4a) [82]. Plasma electron transfer led to the fluorescence quenching of $\mathrm{Ag} / \mathrm{Ag}_{2} \mathrm{~S} \mathrm{JNP}$; however, $\mathrm{H}_{2} \mathrm{O}_{2}$ could etch the surface $\mathrm{Ag}$ and thus activate its fluorescent property. As shown in Figure $4 \mathrm{~b}, \mathrm{c}$, the $\mathrm{Ag}$ in $\mathrm{Ag} / \mathrm{Ag}_{2} \mathrm{~S} \mathrm{JNP}$ was gradually etched in the presence of $\mathrm{H}_{2} \mathrm{O}_{2}$ within $30 \mathrm{~h}$, resulting in a slight change in absorbance at $808 \mathrm{~nm}$, while the NIR-II fluorescence intensity at $1250 \mathrm{~nm}$ was significantly enhanced. In vivo and ex vivo NIR-II fluorescence imaging indicated that mice injected with $\mathrm{Ag} / \mathrm{Ag}_{2} \mathrm{~S}$ JNP generated obvious fluorescence at the tumor site which could be inhibited by $\mathrm{N}$-acetyl cysteine (NAC) (Figure $4 \mathrm{~d}, \mathrm{e})$. However, $\cdot \mathrm{OH}$ is the ROS with the strongest oxidation activity in living organisms, and it can attack biological substrates such as biological proteins and DNA, causing severe oxidative damage $[83,84]$. Compared with conventional electron paramagnetic resonance (EPR), detection of $\cdot \mathrm{OH}$, fluorescence imaging is noninvasive and highly sensitive, whereas NIR-II fluorescence imaging has deeper tissue penetrability and lower spontaneous background fluorescence [85-87]. In 2019, Feng et al. reported a NIR-II fluorescent probe, Hydro-1080, which could be activated by ·OH (Figure 4f) [88]. Due to the decrease in conjugation and coplanarity in Hydro-1080, there was no obvious NIR-II fluorescence intensity. After the formation of Et- 1080 by $\cdot \mathrm{OH}$ oxidation, the fluorescence recovered with the recovery of the conjugation system. As shown in Figure $4 \mathrm{~g}, \mathrm{~h}$, with a concentration of $\cdot \mathrm{OH}$ from 0.01 to $1.60 \mu \mathrm{M}$, the absorption intensity at $1021 \mathrm{~nm}$ was enhanced, and the fluorescence intensity at $1044 \mathrm{~nm}$ was also enhanced, showing the responsiveness of Hydro-1080 to $\cdot \mathrm{OH}$. The production of $\cdot \mathrm{OH}$ in mouse liver could be induced by injecting acetaminophen (APAP) into mice. After different doses of APAP were injected into mice, and they were then injected with Hydro-1080, the mice showed a dose-dependent fluorescence increase in NIR-IIa (1300-1400 nm), and inhibitor 1-aminobenzotriazole (ABT) significantly inhibited the process (Figure $4 \mathrm{i}, \mathrm{j}$ ).

a
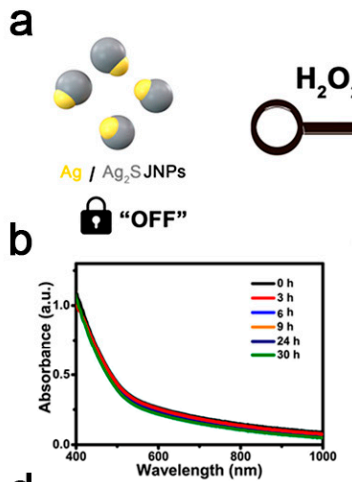

d

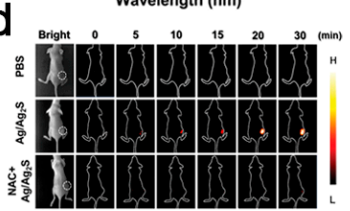

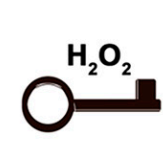
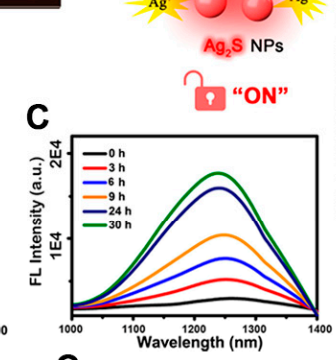

e

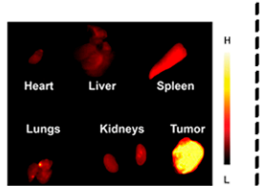

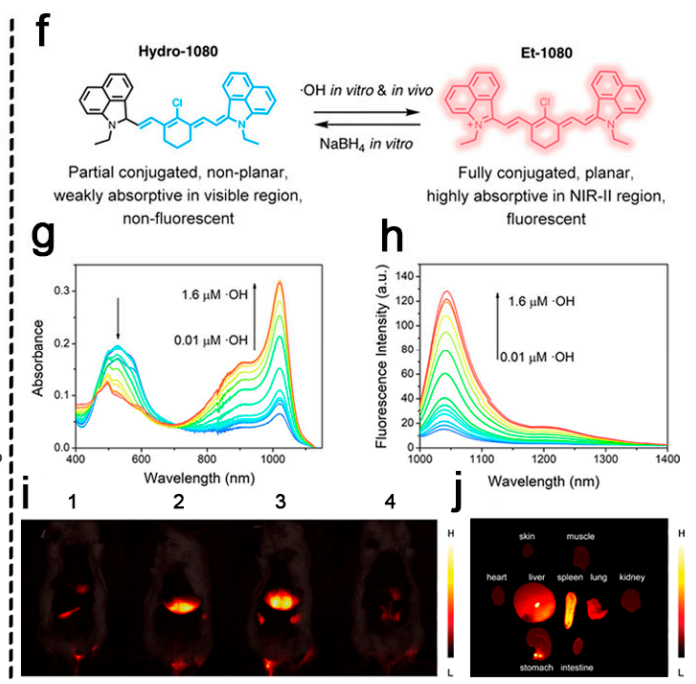

Figure 4. (a) Schematic representation of the mechanism of $\mathrm{H}_{2} \mathrm{O}_{2}$-activatable nanoprobe $\mathrm{Ag} / \mathrm{Ag}_{2} \mathrm{~S}$ JNPs for NIR-II fluorescence imaging in vivo. (b) Electronic absorption and (c) fluorescence spectra of $\mathrm{Ag} / \mathrm{Ag}_{2} \mathrm{~S} J N P s$ after treatment with $\mathrm{H}_{2} \mathrm{O}_{2}$ at different time points. (d) NIR-II fluorescence imaging of tumor-bearing mice at different time points after $\mathrm{Ag} / \mathrm{Ag}_{2} \mathrm{~S} \mathrm{JNP}$ injection in vivo. (e) NIR-II fluorescence imaging of tumor and main organs excised from the $\mathrm{Ag} / \mathrm{Ag}_{2} \mathrm{~S}$ treated mice group. Reproduced with permission [82]. Copyright 2021, American Chemical Society. (f) Chemical structures and mutual conversion processes of Hydro-1080 and Et-1080. (g) Electronic absorption and (h) fluorescence spectra of Hydro-1080 after reaction with different concentrations of ·OH. (i) NIR-IIa fluorescence imaging of mice injected first with different doses of APAP $(0,300,500,500 \mathrm{mg} / \mathrm{kg})$ and then with Hydro- $1080(1 \mathrm{mM}, 5 \mathrm{~mL} / \mathrm{kg})$. In addition, the fourth mouse in the picture was intraperitoneally pre-injected with ABT (100 mg/kg) $24 \mathrm{~h}$ before injecting APAP. 1: Hydro-1080; 2: $\operatorname{APAP}(300 \mathrm{mg} / \mathrm{kg})+$ Hydro-1080; 3: APAP (500 mg/kg) + Hydro-1080; 4: APAP (500 mg/kg) + Hydro-1080 + ABT (100 mg/kg). (j) NIR-IIa fluorescence imaging of main organs and tissues of mice injected with APAP (500 mg/kg) and Hydro-1080. Reproduced with permission [88]. Copyright 2019, American Chemical Society. 
Hypochlorous acid $(\mathrm{HClO})$ is a highly oxidation-active oxo-acid of chlorine, which is endogenously produced from chloride ions and $\mathrm{H}_{2} \mathrm{O}_{2}$ catalyzed by myeloperoxidase (MPO) in neutrophils [89-91]. As a signal molecule, $\mathrm{HClO}$ is involved in regulating a variety of physiological processes [89-91]. However, excessive production of $\mathrm{HClO}$ will cause tissue damage and the formation of a variety of diseases, including cancer, arthritis, and lymphadenitis [92,93]. Ge et al. synthesized a novel NIR-II organic fluorescent probe, SETT, which could be activated by HClO-specific oxidation and showed a highly sensitive response [94]. Furthermore, SETT was loaded on the surface of down-conversion nanoparticles (DCNP) doped with $\mathrm{Er}^{3+}$, obtaining the NIR-II ratiometric nanoprobe DCNP@SeTT. Interestingly, upon light irradiation at a wavelength of $980 \mathrm{~nm}$, the fluorescence intensity of SETT at $1150 \mathrm{~nm}$ decreased with an increasing concentration of $\mathrm{HClO}$, while that of DCNP at $1550 \mathrm{~nm}$ was unchanged. Therefore, the ratiometric fluorescence signal $(\mathrm{I} 1150 \mathrm{~nm} / \mathrm{I} 1550 \mathrm{~nm})$ was linearly correlated with the concentration of HClO. In addition, the DCNP@SeTT probe could be used for HClO-responsive NIR-II fluorescence imaging of rabbit osteoarthritis and mouse tumors. Tang et al. reported that a non-fullerene acceptor (ITTC) was blended with a semiconducting polymer donor (PDF) to construct a NIR-II fluorescent probe (SPNPs) that could be activated by $\mathrm{ClO}^{-}$(Figure 5a) [95]. Upon close contact of ITTC and PDF, the donor-acceptor interaction caused PET to quench the fluorescence of PDF. As shown in Figure 5b, with an increase in ITTC content, the NIR-II fluorescence quenching degree of SPNPs also increased. Encouragingly, $\mathrm{ClO}^{-}$could oxidize and degrade ITTC, allowing the fluorescence of SPNP25 (25\% doping amount) to recover, while other reactive oxygen species and reducing species could not produce this change, indicating the specificity of this activation process (Figure $5 c$,d). After intravenous injection of SPNP25, the fluorescence at the inflammatory sites of the mice was significantly enhanced, while there was no fluorescence at the normal sites (Figure 5e). It is worth noting that NAC significantly inhibited fluorescence at sites of inflammation in mice.

a
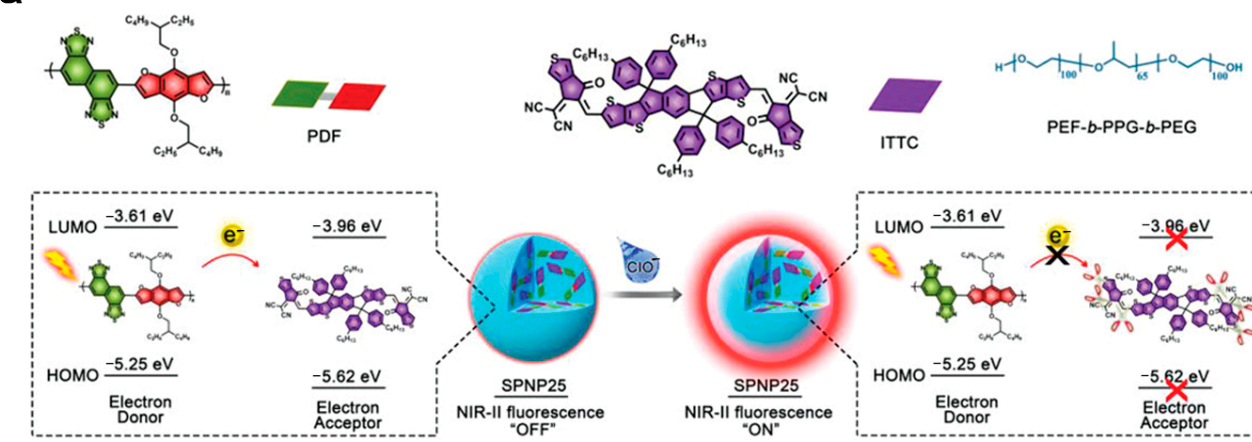

b
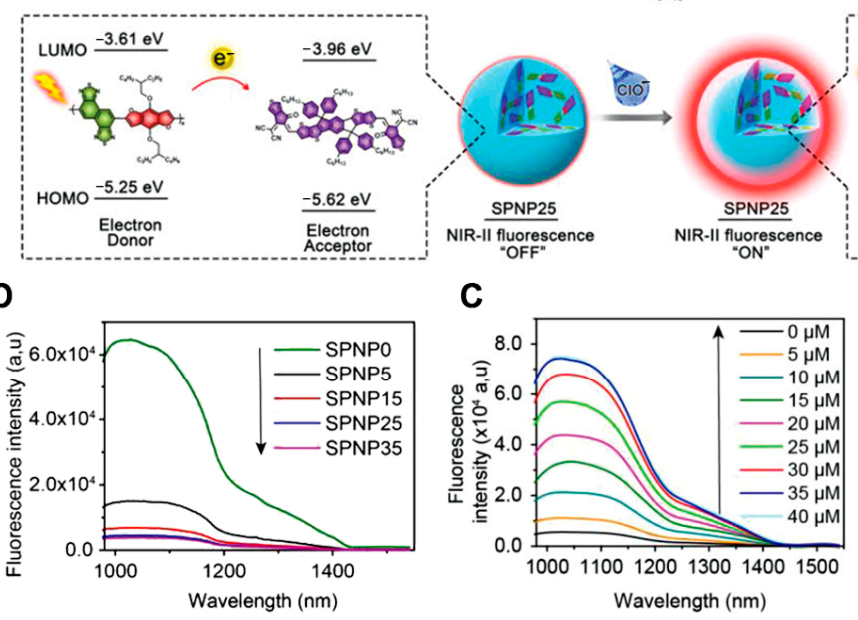

C

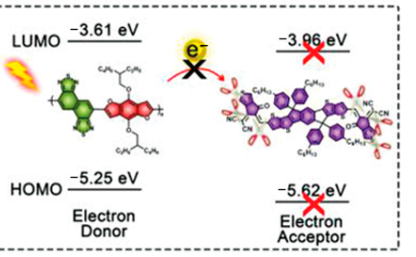

\section{C}

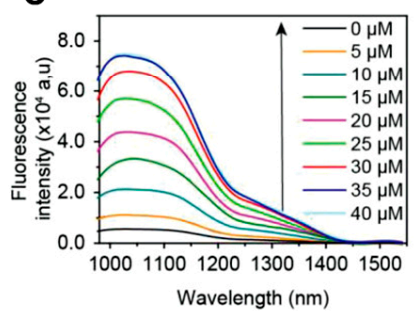

d

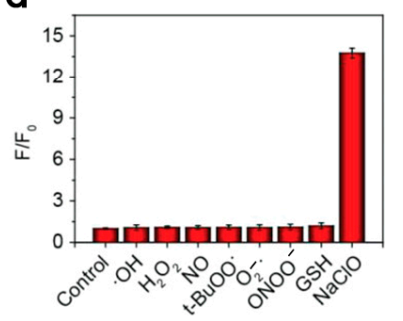

e
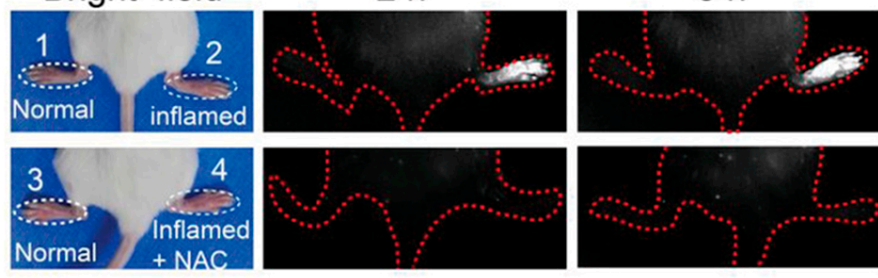

$10 \mathrm{~h}$

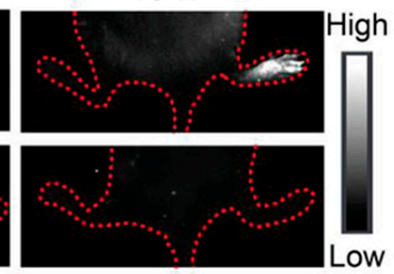

Figure 5. (a) Chemical structures of PDF, ITTC, and PEG-b-PPG-b-PEG, and the mechanism of nanoprobe 
SPNP25 for endogenous $\mathrm{ClO}^{-}$detection. (b) Fluorescence intensity of SPNPs doped with different amounts of ITTC. (c) Fluorescence spectra of the nanoprobe SPNP25 after reaction with various concentrations of $\mathrm{ClO}^{-}$. (d) Fluorescence intensity ratios of nanoprobe SPNP25 toward $\mathrm{ClO}^{-}(40 \mu \mathrm{M})$ and various biochemically related analytes $(100 \mu \mathrm{M})$. (e) Time-dependent fluorescence imaging in the inflammatory and normal sites of LPS-pretreated and LPS/NAC-treated mice after injection of SPNP25. Reproduced with permission [95]. Copyright 2019, WILEY-VCH.

\subsection{RNS}

RNS are highly reactive biological oxidation species containing nitrogen, mainly including nitric oxide (NO), peroxynitrite $\left(\mathrm{ONOO}^{-}\right)$, and S-nitrosothiols (RSNO) [21,96]. In common with ROS, RNS play an important role in oxidation processes under physiological conditions which are related to oxidative stress, brain diseases, cancer, and inflammation [97-99]. In fact, $\mathrm{ONOO}^{-}$is not only related to the nitration of proteins in immune cells in tumors, affecting the immunosuppression of tumors, but is also related to the occurrence and development of brain injury [100,101].

Traumatic brain injury (TBI) is highly likely to cause disability and death in humans unless it can be easily diagnosed at an early stage [102]. Currently, clinical diagnosis of TBI is mainly achieved using magnetic resonance imaging (MRI) and computed tomography (CT), but these are difficult to use for real-time early diagnosis of TBI. As reported, $\mathrm{ONOO}^{-}$ is a biomarker of early TBI which is accompanied by the occurrence and development of TBI $[103,104]$. Therefore, the occurrence of early TBI can be diagnosed by monitoring the biomarker $\mathrm{ONOO}^{-}$. In 2020, Li et al. reported an activated NIR-II fluorescent probe (V\&A@ $\mathrm{Ag}_{2} \mathrm{~S}$ ) composed of a targeting group (VCAM1 binding peptide), an A1094 chromophore NIR absorber, and $\mathrm{Ag}_{2} \mathrm{~S}$ QD (Figure 6a) [105]. Specifically, there is a large overlap between the NIR-II fluorescence emission spectrum of $\mathrm{Ag}_{2} \mathrm{~S} \mathrm{QD}$ and the absorption spectrum of A1094, leaving the fluorescence of V\&A@ $\mathrm{Ag}_{2} \mathrm{~S}$ in the "off" state. However, when $\mathrm{ONOO}^{-}$was present, A1094 was oxidized and its absorption peak disappeared, resulting in the NIR-II fluorescence signal of V\&A@ $\mathrm{Ag}_{2} \mathrm{~S}$ being turned "on". In addition, the VCAM1 binding peptide enabled V\&A@ $\mathrm{Ag}_{2} \mathrm{~S}$ to target inflamed endothelium expressing VCAM1. As shown in Figure $6 \mathrm{~b}, \mathrm{ONOO}^{-}$enhanced the fluorescence intensity of V\&A@ $\mathrm{Ag}_{2} \mathrm{~S}$ at $1050 \mathrm{~nm}$, and the magnitude of the enhancement had a linear relationship with the concentration of $\mathrm{ONOO}^{-}$. Apart from $\mathrm{ONOO}^{-} / \mathrm{ClO}^{-}$, other common anions and cations could not activate V\&A@ $\mathrm{Ag}_{2} \mathrm{~S}$, showing the specificity of this activation mode (Figure $6 \mathrm{c}$ ). Encouragingly, 3-morpholinosydnonimine hydrochloride (SIN-1) was used to induce ONOOproduction by the cells, and cell experiments showed that in the presence of $\mathrm{ONOO}^{-}$an obvious NIR-II fluorescence signal appeared after V\&A@ $\mathrm{Ag}_{2} \mathrm{~S}$ uptake by human umbilical vein endothelial cells (HUVECs), whereas the control group did not exhibit this process (Figure 6d). In vivo experiments on TBI mice showed that V\&A@Ag $\mathrm{S}$ could be activated by $\mathrm{ONOO}^{-}$, showing excellent NIR-II fluorescence imaging. In the control group, the "always on" V@ $\mathrm{Ag}_{2} \mathrm{~S}$ probe was distributed over the whole brain region without specificity, while A@ $\mathrm{Ag}_{2} \mathrm{~S}$ exhibited no obvious fluorescence signal. Notably, V\&A@Ag $\mathrm{S}$ could not produce an obvious fluorescence signal in healthy mice, indicating that the "turned on" probe showed excellent specificity in biosensor and imaging applications (Figure 6e).

Ischemic stroke is also a brain disease, which is highly likely to cause death and disability in humans if it cannot be easily diagnosed at an early stage [106,107]. Similarly, $\mathrm{ONOO}^{-}$is a biomarker of ischemic stroke and therefore provides the possibility of early diagnosis of the disease $[103,108]$. In 2021, Yang et al. reported a V\&C/PbS@Ag $\mathrm{Ag}_{2}$ nanoprobe modified by VCAM1 binding peptide and Cy7.5 fluorophores, which could be activated by $\mathrm{ONOO}^{-}$to produce obvious NIR-II fluorescence intensity (Figure 6f) [109]. Meanwhile, the VCAM1 binding peptide provided V\&C/PbS@Ag 2 Se with the ability to target ischemic stroke regions, while the Cy7.5 fluorophores and PbS@Ag $\mathrm{Se}_{\mathrm{QD}}$ engendered competitive absorption to turn off the NIR-II fluorescence. As shown in Figure $6 \mathrm{~g}$, the stability of $\mathrm{PbS}$ modified by $\mathrm{Ag}_{2} \mathrm{Se}$ was significantly improved, and no significant change in fluorescence occurred within 10 days. Interestingly, both $\mathrm{PbS} @ \mathrm{Ag}_{2} \mathrm{Se}$ 
and $\mathrm{V} / \mathrm{PbS@} \mathrm{Ag}_{2} \mathrm{Se}$ exhibited obvious fluorescence at $1616 \mathrm{~nm}$, while the fluorescence of $\mathrm{V} \& \mathrm{C} / \mathrm{PbS} @ \mathrm{Ag}_{2} \mathrm{Se}$ was quenched (Figure 6h). Absorption-competition-induced emission (ACIE) was first proposed by Zhang et al. Specifically, organic dye acted as the absorptioncompetition acceptor of the fluorescent probe, significantly inhibiting the fluorescence emission of the fluorescent probe. ACIE technology could be used not only for monitoring drug release but also for in situ NIR sensing of biomarkers [110]. In addition, after HUVECs were incubated with SIN-1 and V\&C/PbS@Ag 2 Se, the cells showed an obvious NIR-II fluorescence signal; conversely, in the absence of SIN-1 no NIR-II fluorescence signal was observed (Figure 6i). Furthermore, in vivo experiments showed that $\mathrm{ONOO}^{-}$activated $\mathrm{V} \& \mathrm{C} / \mathrm{PbS} @ \mathrm{Ag}_{2} \mathrm{Se}$ and lit up its NIR-II fluorescent signal (Figure 6j).

a

b

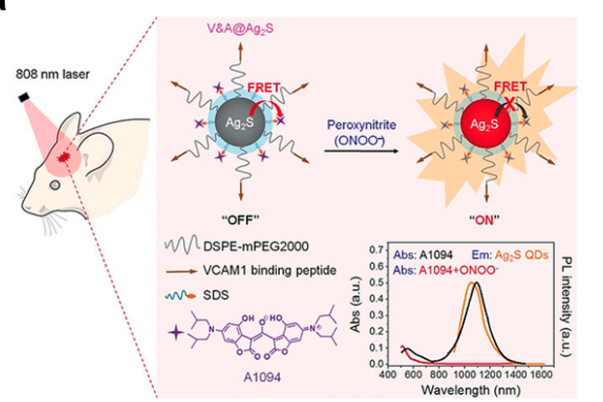

C

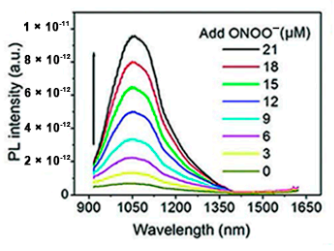

d

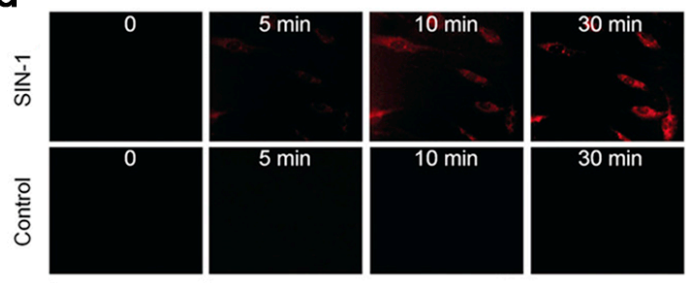

e

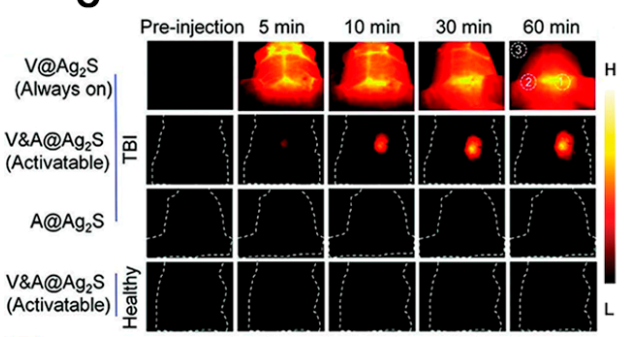

i

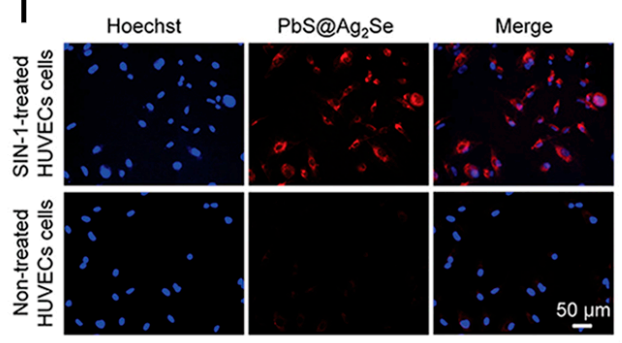

j

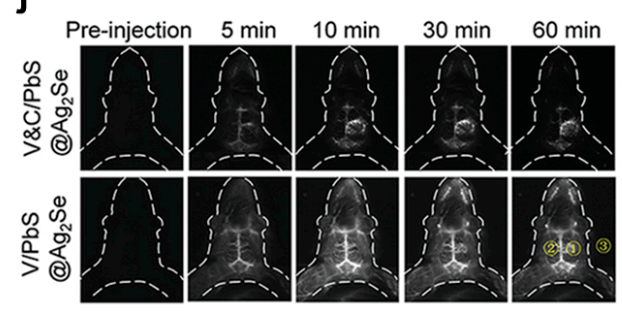

Figure 6. (a) Schematic diagram of the preparation process of the NIR-II nanoprobe V\&A@ $\mathrm{Ag}_{2} \mathrm{~S}$ and the mechanism of detecting $\mathrm{ONOO}^{-}$in vivo. (b) Photoluminescence spectra of $\mathrm{V} \& \mathrm{~A} @ \mathrm{Ag}_{2} \mathrm{~S}(50 \mu \mathrm{g} / \mathrm{mL})$ after reaction with the different concentrations of $\mathrm{ONOO}^{-}$. (c) Fluorescence intensity ratios of $\mathrm{V} \& \mathrm{~A} @ \mathrm{Ag}_{2} \mathrm{~S}(10 \mu \mathrm{g} / \mathrm{mL})$ upon the addition of different ions and RNS/ROS analytes $(20 \mu \mathrm{M})$. (d) Fluorescence microscopy images of HUVECs after incubation with V\&A@Ag $\mathrm{S}$ in the presence and absence of SIN-1. (e) Time-dependent fluorescence imaging in TBI and healthy mice after different treatments. Reproduced with permission [105]. Copyright 2020, WILEY-VCH. (f) Schematic diagram of the design strategy of the NIR-II nanoprobe $\mathrm{V} \& \mathrm{C} / \mathrm{PbS} @ \mathrm{Ag}_{2} \mathrm{Se}$ and the mechanism of detecting $\mathrm{ONOO}^{-}$in ischemic stroke model mice. (g) Time-dependent 
fluorescence spectra of PbS@ $\mathrm{Ag}_{2} \mathrm{Se}$-PEG QDs in PBS of pH 7.4. (h) Electronic absorption and fluorescence spectra of V\&C/PbS@Ag 2 Se, V/PbS@ $\mathrm{Ag}_{2} \mathrm{Se}$, and PbS@Ag $2 \mathrm{Se}$. (i) Fluorescence microscopy images of HUVECs after incubation with V\&C/PbS@ $\mathrm{Ag}_{2}$ Se in the presence and absence of SIN-1. (j) Time-dependent NIR-II fluorescence imaging of early ischemic stroke model mice after treatment with V\&C/PbS@ $\mathrm{Ag}_{2} \mathrm{Se}$ and V/PbS@Ag 2 Se. Reproduced with permission [109]. Copyright 2021, WILEY-VCH.

In contrast to ROS, NO is a widely existing messenger molecule in the human body which plays an important role in cardiovascular, cerebrovascular, immune system and nervous system processes [111]. It is noteworthy that NO was considered as a biomarker of drug-induced hepatotoxicity [112,113]. Iverson et al. reported a NIR-II fluorescent probe, PEG-(AAAT)7-SWNTs, produced by covering the NO-sensitive DNA oligonucleotide ds(AAAT)7 on the surface of SWCNTs [114]. The PEG-(AAAT)7-SWNTs nanoprobe could be used to investigate the production of NO by inflammation in vivo. In 2019, Tang et al. reported an organic semiconductor nanoprobe (AOSNP) activated by NO for monitoring drug-induced hepatotoxicity, which was obtained by the amidation reaction of the NOsensitive organic semiconducting group (FTBD) and poly (styrene-co-maleic anhydride) (PSMA) polymer [115]. Notably, in the presence of NO, FTBD could transform its receptor unit (benzo[c] [1,2,5] thiadiazole-5,6-diamine) into benzotriazole derivatives, realizing the conversion of fluorescence from NIR-I to NIR-II. NO significantly increased the NIR-II fluorescence intensity of AOSNP and changed the color of the AOSNP solution. However, other reactive oxygen species $\left(\mathrm{H}_{2} \mathrm{O}_{2}, \cdot \mathrm{OH}, \mathrm{O}_{2}{ }^{\bullet-}\right.$, and $\left.\mathrm{ONOO}^{-}\right)$and reducing substances (glutathione and GSH) could not enhance the fluorescence of AOSNP, indicating the specificity of the activation mode. After co-incubation with AOSNP and HepG2 hepatoma cells, the cells showed an obvious NIR-II fluorescence signal, and the additional inhibitor NAC significantly inhibited this process. Interestingly, APAP induced a large amount of $\mathrm{NO}$ to produce hepatotoxicity in mice. In vivo fluorescence imaging indicated that AOSNP could be activated by NO generated from APAP-treated mice to produce obvious NIR-II fluorescence signals, while this process could be inhibited by inhibitor NAC.

\subsection{RSS}

RSS mainly include thiols (GSH and Cys), $\mathrm{H}_{2} \mathrm{~S}$, and persulfides (R-S-SH/ $\mathrm{H}_{2} \mathrm{~S}_{2}$ ) [116,117]. In fact, the level of intracellular GSH is higher than that of extracellular GSH, and the concentration of GSH in tumor tissue is also higher than that in normal tissue [26,118]. $\mathrm{Li}$ et al. reported $\mathrm{Ln}^{3+}$-doped nanoparticles (LnNPs) probe using the large spectral overlap between the absorption spectrum of $\mathrm{Ln}^{3+}$ and the emission spectrum of heptamethine cyanine, which could be activated by GSH for high-resolution biological imaging [119]. In contrast to ROS and RNS, RSS not only played the role of oxidation, but also played the role of reduction. $\mathrm{H}_{2} \mathrm{~S}$ is both a special biological signaling molecule and an important biomarker for early cancer [120-122]. In 2018, Shi et al. reported a $\mathrm{H}_{2} \mathrm{~S}$-activatable nanodrug (Nano-PT) for NIR-II fluorescence imaging of colorectal cancer (CRC) [116]. Nano-PT is a monochlorinated BODIPY derivative which produces a nucleophilic reaction with $\mathrm{H}_{2} \mathrm{~S}$. Interestingly, Nano-PT not only produced activatable NIR-II fluorescence emission, but also produced high-efficiency NIR absorption, which realized NIR-II-fluorescence-guided PTT. Therefore, PTT mediated by Nano-PT achieved highly specific CRC treatment guided by NIR-II fluorescence imaging, promoting the development of precision medicine.

In 2021, Liu et al. designed and synthesized a series of $\mathrm{H}_{2} \mathrm{~S}$-activated NIR-II fluorescence probes, WH-X (WH-1, WH-2, WH-3, and WH-4), which were modified by a 4-nitrothiophenol fluorescence quencher (Figure 7a) [121]. The maximum emission wavelength of WH-3 was $1205 \mathrm{~nm}$, which was superior to the other three compounds, and it showed excellent NIR-II fluorescence characteristics. Theoretical calculations showed that substitution of the WH-2-HS acceptor successfully reduced the gap between the highest occupied molecular orbital (HOMO) and the lowest unoccupied molecular orbital (LUMO) (Figure $7 \mathrm{~b}$ ). By extending the conjugation region in WH-3-HS and WH-4-HS, the ICT process was strengthened, leading to the gap being narrowed further. As shown in Figure $7 \mathrm{c}$, 
WH-3 showed a concentration-dependent fluorescence enhancement in the presence of $\mathrm{NaHS}$. Using $\mathrm{H}_{2} \mathrm{~S}$-overexpressing HCT-116 colon cancer cells as a model, intracellular fluorescence imaging also showed that NaHS significantly depleted $\mathrm{WH}-3$, whereas the inhibitor aminooxyacetic acid (AOAA) inhibited this depletion (Figure 7d). In vivo experiments showed that WH-3 produced an NIR-II fluorescence signal at the tumor site, while the inhibitor AOAA inhibited this process, indicating that $\mathrm{WH}-3$ could be activated by $\mathrm{H}_{2} \mathrm{~S}$ (Figure 7e).

a

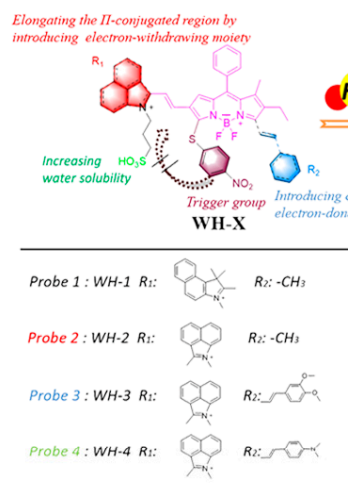

C

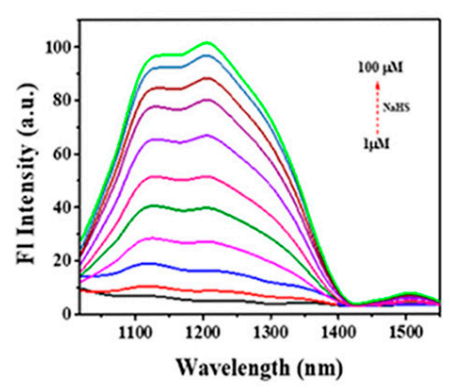

b

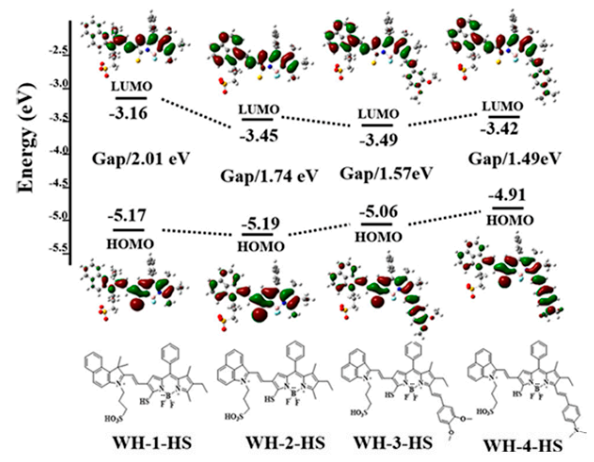

d

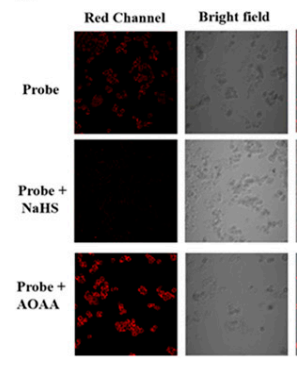

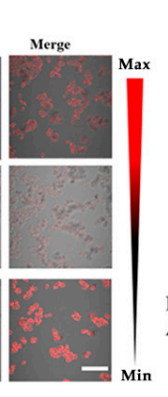

e Bright

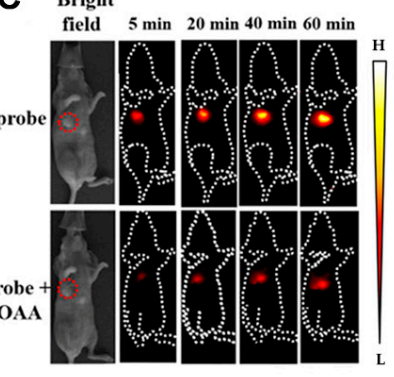

Figure 7. (a) Schematic illustration of the construction of several $\mathrm{H}_{2} \mathrm{~S}$-activatable NIR-II fluorescence probes $\mathrm{WH}-\mathrm{X}$ (WH-1, WH-2, WH-3, and WH-4). (b) Theoretical calculations used to verify the design strategy. The HOMO and LUMO energy levels of WH-X-HS were computed. (c) Fluorescence spectra of WH-4 in the presence of different concentrations of NaHS under the irradiation of $980 \mathrm{~nm}$ laser. (d) Intracellular fluorescence imaging of HCT-116 cells incubated with WH-3, WH-3 + NaHS, and WH-3 + AOAA. (e) NIR-II fluorescence imaging of tumor-bearing mice at various time points after treatment with WH-3 and WH-3 + AOAA. Reproduced with permission [121]. Copyright 2021, American Chemical Society.

\subsection{Hypoxia}

Hypoxia is an important characteristic of solid tumors which is related to tumor migration, invasion, and deterioration [123,124]. The occurrence of hypoxia greatly limits the therapeutic efficacy of chemotherapy, photodynamic therapy (PDT), and sonodynamic therapy (SDT) $[125,126]$. Therefore, it is significant to design hypoxia-activated nanomaterials for the diagnosis and treatment of tumors [127]. Meng et al. coupled IR-1048 dye and 2-(2-nitroimidazolyl) ethylamine, MZ, to develop a novel dye IR1048-MZ, achieving hypoxia-activated NIR-II/PA tumor-imaging-guided PTT (Figure 8a) [126]. Theoretical calculations showed that the HOMO and LUMO of IR1048-MZH were lower than those of IR1048-MZ, indicating enhanced fluorescence emission intensity. Nitroreductase (NTR) overexpressed by hypoxic tumor tissue reduced the nitro group of IR1048-MZ to an amine group and activated the NIR-II fluorescence signal of IR1048-MZ. As shown in Figure 8b, the fluorescence of the IR1048-MZ probe at the maximum emission wavelength $(1046 \mathrm{~nm})$ was suppressed, whereas it was significantly enhanced in the presence of NTR. In addition, with an increase in NTR concentration, the NIR-II fluorescence intensity also increased, 
and this change showed a good linear relationship (Figure 8c). Moreover, in vivo imaging showed that IR1048-MZ resulted in the A549 tumor of nude mice producing an obvious fluorescence signal, while no obvious signal was found in other parts (Figure $8 \mathrm{~d}$ ). The maximum value of the tumor background was 30, indicating that IR1048-MZ was an excellent probe for hypoxia without background.

a

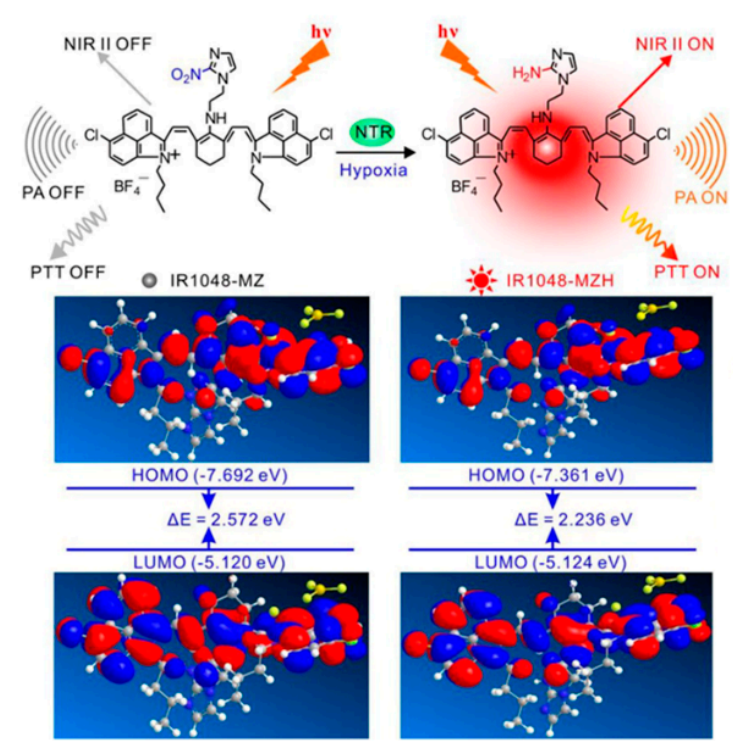

b

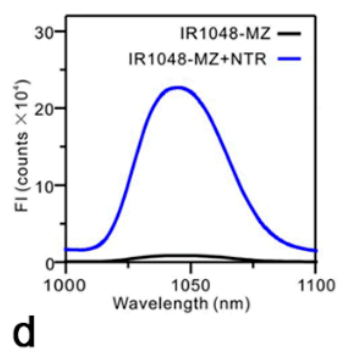

C
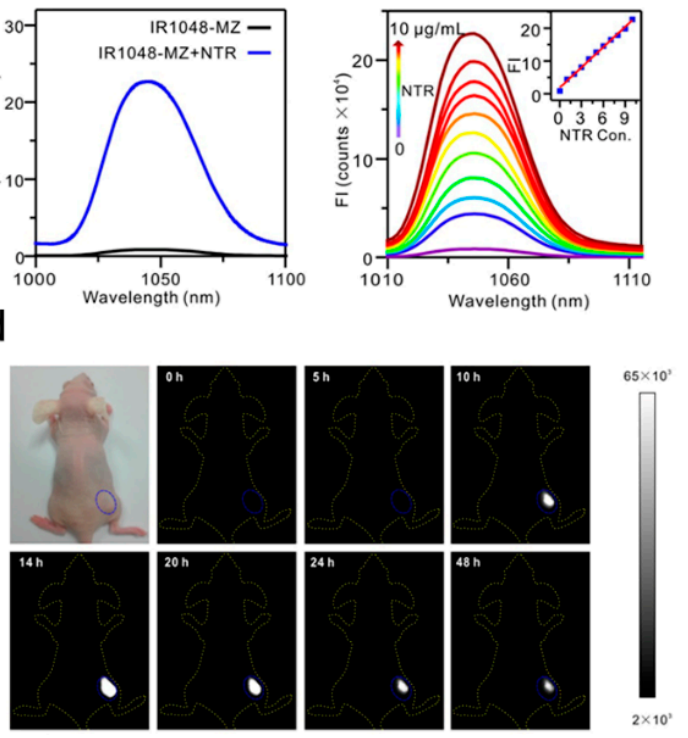

Figure 8. (a) Schematic diagram of the catalyzed mechanism of IR1048-MZ for hypoxia-activated NIR-II/PA tumor imaging. HOMO and LUMO energy levels of IR1048-MZ and IR1048-MZH were obtained by theoretical calculation. (b) Fluorescence spectra of IR1048-MZ with and without the addition of NTR. (c) NIR-II fluorescence spectra of IR1048-MZ (5 $\mu \mathrm{g} / \mathrm{mL})$ in response to various concentrations of NTR. (d) Time-dependent NIR-II fluorescence imaging of tumor-bearing mice after injection of IR1048-MZ (40 $\mu \mathrm{g} / \mathrm{mL}, 200 \mu \mathrm{L}$ ). Reproduced with permission [126]. Copyright 2018, Creative Commons.

\subsection{Viscosity}

Viscosity is a major factor in the microenvironment of the living body which is related to various physiological and pathological processes [22,128]. Viscosity abnormalities are associated with many diseases, such as diabetes and Alzheimer's disease [129,130]. Consequently, a viscosity-activated NIR-II fluorescent probe can be used to analyze and detect the viscosity level of organisms to further explore the occurrence and development of related diseases. In 2020, Dou et al. developed a series of viscosity-activated NIR-II fluorescent probes using BODIPY derivatives modified by 1-ethyl-2-methyl-benz[c,d] iodolium salt as a precursor (Figure 9a) [131]. It is worth emphasizing that the substituents of WD-OCH and $\mathrm{WD}-\mathrm{NME}_{2}$ were strong electron-donating groups and exhibited longer NIR-II fluorescence emission wavelengths (Figure 9b). Interestingly, in the ethanol-glycerol system with different viscosities, the intensities of $\mathrm{WD}-\mathrm{NO}_{2}$ at the maximum absorption wavelength and the maximum emission wavelength increased with an increase in viscosity, while the other three molecules also showed similar properties (Figure 9c,d). Briefly, at low viscosity, the conjugated structure was destroyed and caused an increase in nonradiative energy consumption, thereby leading to the weakening of the fluorescence intensity. However, at high viscosity, intramolecular rotation was restricted, causing fluorescence recovery. As shown in Figure 9e,f, monensin (Mon), nystatin (Nys), and lipopolysaccharide (LPS) could change the viscosity in mice. In vivo fluorescence imaging showed that the livers of mice treated with Mon, Nys, and LPS, which received intraperitoneal injections of WD-NO exhibited significant fluorescence intensity, indicating that $\mathrm{WD}-\mathrm{NO}_{2}$ is an effective tool for studying the change of viscosity in vivo. 
a

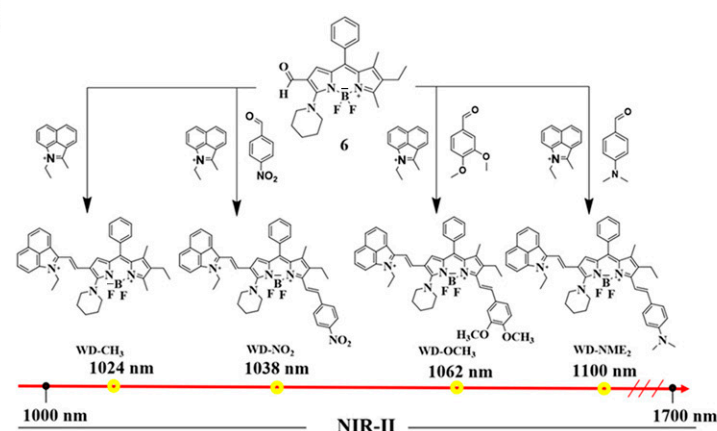

b

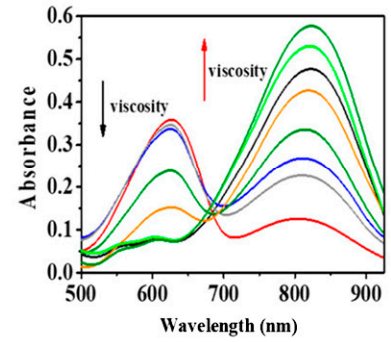

C

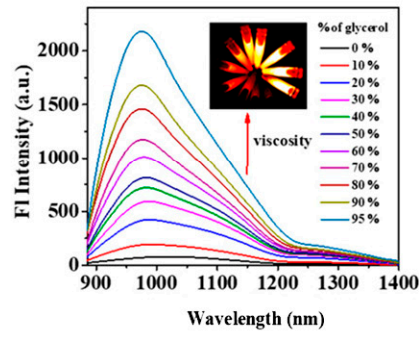

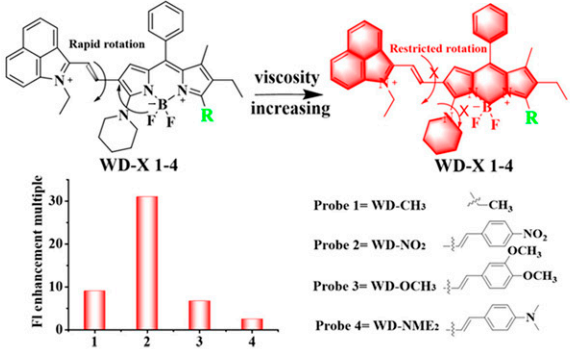

d

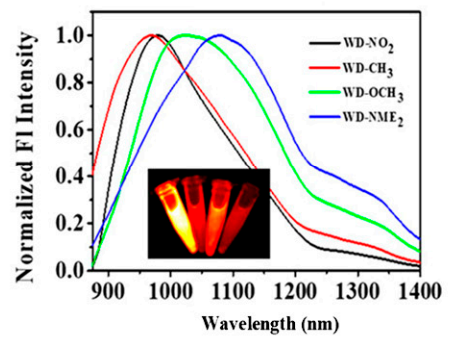

e Probe Probe + Mon Probe + Nys Probe + LPS

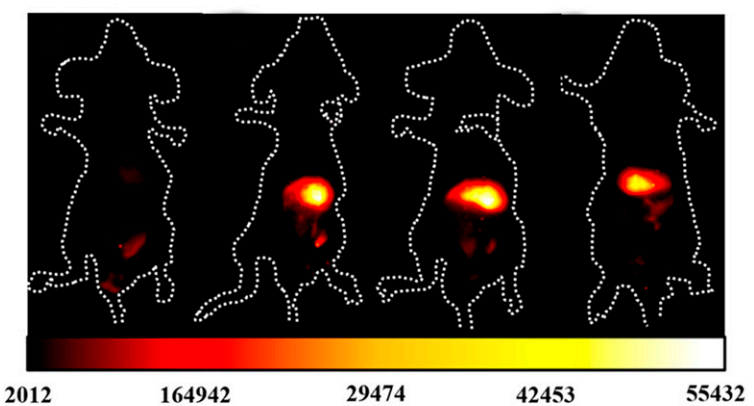

f

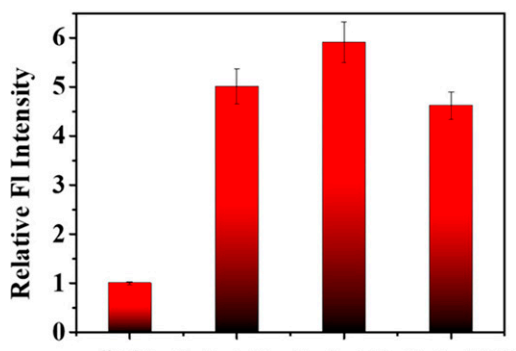

Probe Probe + Mon Probe + Nys Probe + LPS

Figure 9. (a) Schematic illustration of the design strategy of viscosity-activatable fluorescence probes $\mathrm{WD}-\mathrm{X}\left(\mathrm{WD}-\mathrm{CH}_{3}, \mathrm{WD}-\mathrm{NO}_{2}, \mathrm{WD}-\mathrm{OCH}_{3}\right.$, and $\left.\mathrm{WD}-\mathrm{NME}_{2}\right)$. Chemical structures and synthetic routes of WD-X (left) and mechanism of WD-X for viscosity-activatable NIR-II fluorescence imaging (right). (b) Electronic absorption and (c) fluorescence spectra of WD- $\mathrm{NO}_{2}(20 \mu \mathrm{M})$ in the ethanol-glycerol system with different viscosities. Inset shows fluorescence images of $\mathrm{WD}-\mathrm{NO}_{2}$ in the ethanol-glycerol system with different glycerol ratios. (d) Normalized NIR-II fluorescence spectra of WD-X (WD$\mathrm{NO}_{2}, \mathrm{WD}-\mathrm{CH}_{3}, \mathrm{WD}-\mathrm{OCH}_{3}$, and $\mathrm{WD}-\mathrm{NME}_{2}$ ) in the system with $95 \%$ glycerol. Inset shows the corresponding fluorescence images under the irradiation of $808 \mathrm{~nm}\left(40 \mathrm{~mW} / \mathrm{cm}^{2}\right)$ laser. (e) Fluorescence imaging and (f) normalized relative fluorescence intensity of mice after treatment with $\mathrm{WD}-\mathrm{NO}_{2}, \mathrm{WD}-\mathrm{NO}_{2}+\mathrm{Mon}, \mathrm{WD}-\mathrm{NO}_{2}+\mathrm{Nys}$, and $\mathrm{WD}-\mathrm{NO}_{2}+$ LPS. Reproduced with permission [131]. Copyright 2020, American Chemical Society.

\subsection{Dual-Responsive}

A single activation method cannot effectively deal with the complex and dynamic biological microenvironment, resulting in the phenomenon of nonspecific activation and even false-positive results $[132,133]$. The utilization of two activation methods in the above methods ( $\mathrm{pH}$, enzyme, redox, etc.) to activate the NIR-II fluorescence probe greatly improves the specificity of fluorescence imaging, which can effectively avoid the occurrence of false-positive results [134-136]. Zhang and co-workers developed a dual-activatable theranostic nanoprobe (DATN) which could output dual signals under the double stimulation of NO/acidity in inflammation-related tumors for photoacoustic and photothermal imaging in vivo [137]. DATN showed a higher photoacoustic signal under dual activation, which was 132 times that of acidity alone and 9.8 times that of NO. Under single-factor 
stimulation, DATN increased by about $6{ }^{\circ} \mathrm{C}$. while under dual-factor stimulation it increased by about $27.3^{\circ} \mathrm{C}$, exhibiting the superiority of dual activation. In addition, in the tumor microenvironment, high levels of GSH (1-15 mM) and low $\mathrm{pH}(\mathrm{pH}=5.0-6.8)$ acted as a "dual key" to activate the photosensitizers. Teng et al. reported a photosensitizer, BIBCl-PAE NP, which underwent protonation under acidic conditions, further promoting the reaction of GSH with BIBCl-PAE NP to generate water-soluble BIBSG for PDT [138]. In vitro studies revealed that BIBCl-PAE NP could distinguish normal and cancer cells in cell imaging, while also exhibiting excellent PDT ability. In vivo experiments also showed that BIBCl-PAE NP was rapidly enriched in the tumor site, while specifically "lighting up" the tumor site, showing irreversible therapeutic activity with less effect on normal tissues. Tang et al. utilized NIR-II cyanine dye (IR-1061) to covalently connect hyaluronic acid (HA) and synthesized IR-1061-pendent HA polymers, which could self-assemble into single-lock-and-key-controlled HINPs in water, and then be cross-linked on the surface of HINPs through disulfide to form dual-lock-and-key-controlled HISSNPs (Figure 10a) [139]. HA and disulfide formed the "double locks" to lock HISSNPs in a quenched state, while the overexpressed hyaluronidase (Hyal) and GSH in the tumor microenvironment acted as "dual smart keys" to break HA chains and disulfide bonds enabled the fluorescence recovery of IR-1061. As shown in Figure 10b-d, when a "single smart key" (Hyal or GSH) existed, the fluorescence of HISSNPs was increased by about 3.4 times and 2.9 times, respectively, while when Hyal and GSH existed together, the fluorescence of HISSNPs was increased by about 13.3 times. In vitro cell experiments showed that MCF-7 breast cancer cells produced obvious fluorescence after uptake of HISSNPs, whereas normal cells did not show the phenomenon (Figure 10e). As we know, 6-O-palmitoyl-1-ascorbic acid (an inhibitor of Hyal) and N-ethylmalemide (a thiol scavenger) could significantly inhibit the activation process, while 6-O-palmitoyl-l-ascorbic acid could inhibit the activity of HINPs. In vivo fluorescence imaging indicated that mice injected with HISSNPs generated obvious NIR-II fluorescence at tumor sites with a higher sensitivity than that of HINPs, indicating the sensitivity and specificity of the dual lock and key (Figure 10f). Notably, although the dual-responsive NIR-II fluorescent probe showed excellent specificity, activatable NIR-II fluorescent probes with single activation methods are still in their infancy, and activatable NIR-II fluorescent probes with two activation methods have rarely been reported. 
a

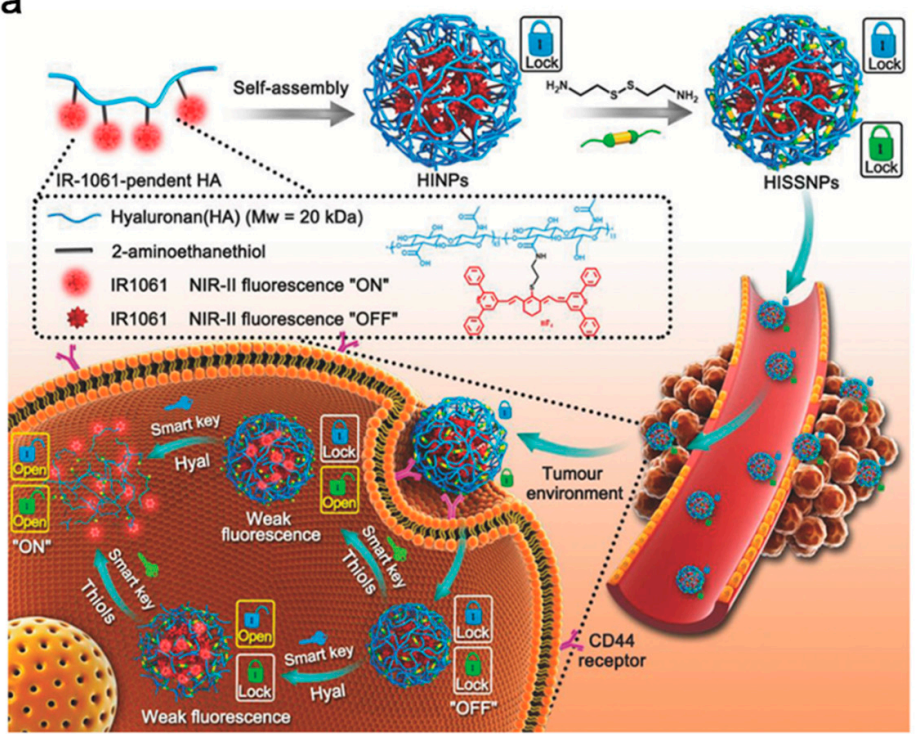

e

MCF-7 Ce

MCF-7 Cells + HA blocking

MCF-7 Cells + Hyal blocking

MCF-7 Cells + thiols blockin

MCF-7 Cells + Hyaltthiols blockin

Normal 3 T3 Cells

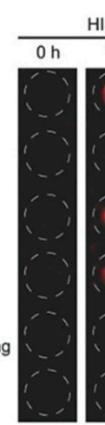

f
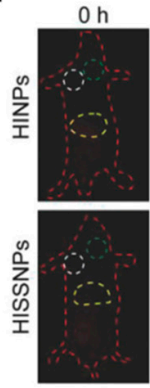

b

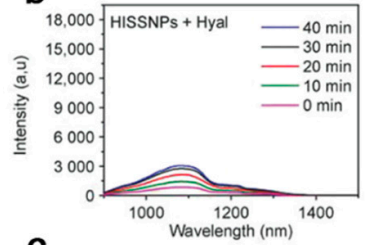

C
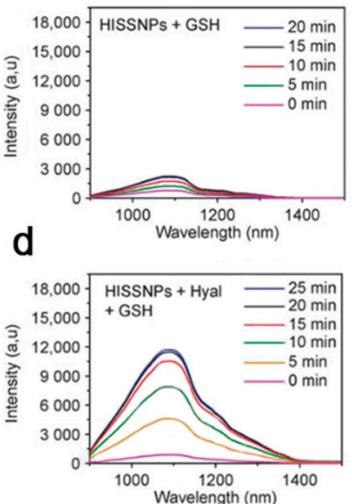

$10 \mathrm{~h}$
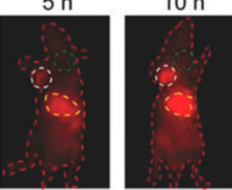

$15 \mathrm{~h}$

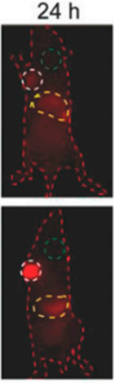

$\operatorname{Min}$

Figure 10. (a) Schematic diagram of the synthetic route of dual-lock-and-key-controlled NIR-II fluorescence probe HISSNPs and its corresponding mechanism for tumor-specific imaging. Timedependent fluorescence (excited at $808 \mathrm{~nm}$ ) spectra of HISSNPs incubated with (b) Hyal, (c) GSH, and (d) Hyal and GSH in PBS. (e) NIR-II fluorescence imaging of 3T3 cells and MCF-7 breast cancer cells at the time points of $0 \mathrm{~h}, 1.5 \mathrm{~h}$, and $3 \mathrm{~h}$ after different treatments. (f) Time-dependent NIR-II fluorescence imaging of MCF-7 cancer xenografts model mice after injection with HISSNPs and HINPs (35 mg/kg). White circle: tumor site; yellow circle: abdominal liver site; green circle: muscle (refers to normal tissue). Reproduced with permission [139]. Copyright 2018, WILEY-VCH.

\section{Summary and Outlook}

Compared with traditional NIR-I fluorescence imaging, NIR-II fluorescence imaging has a deeper tissue penetration depth and a higher SBR. In recent years, a great number of NIR-II fluorescent materials, including SWCNTs, QDs, RENPs, BBTDs, and cyanine dyes were reported to have excellent photophysical and photochemical properties. However, these "always on" fluorescent probes lacked selectivity, showing a low SBR and poor detection sensitivity. On the other hand, the activatable NIR-II fluorescent probe is in an "off" state in normal tissues, while in diseased tissues it can be activated by a specific biomarker to present an "on" state. According to the type of activation mode, these strategies mainly include eight categories: pH, enzyme, ROS, RNS, RSS, hypoxia, viscosity, and dual-responsive. Specifically, the activation mechanisms were mainly the consumption of an inhibitor and changes in the functional group, charge, and conformation. These activatable NIR-II fluorescent probes and their activation strategies and mechanisms are summarized in Table 1. 
Table 1. Representatives of activatable NIR-II fluorescent probes for biomedical applications.

\begin{tabular}{|c|c|c|c|c|c|c|}
\hline $\begin{array}{l}\text { Activation } \\
\text { Mode }\end{array}$ & Probe Name & $\begin{array}{c}\text { Probe } \\
\text { Fluorophores }\end{array}$ & $\begin{array}{l}\text { Activation } \\
\text { Mechanism }\end{array}$ & $\begin{array}{c}\text { Excitation/ } \\
\text { Emission }(\mathrm{nm})\end{array}$ & Biological Model & Refs \\
\hline $\mathrm{pH}$ & BTC1070 & $\begin{array}{l}\text { Pentamethine } \\
\text { cyanine }\end{array}$ & $\begin{array}{c}\text { Protonation, inhibition of } \\
\text { ICT effect }\end{array}$ & $808 / 1000-1300$ & $\begin{array}{l}\text { Simulated gastric fluid } \\
\text { with different } \mathrm{pH}\end{array}$ & [54] \\
\hline $\mathrm{pH}$ & $\mathrm{Ag}_{2} \mathrm{~S} \mathrm{Ve}$ & $\mathrm{Ag}_{2} \mathrm{~S}$ & $\begin{array}{l}\text { Protonation, increased } \\
\text { hydrophilicity }\end{array}$ & $808 / 1250$ & $4 \mathrm{~T} 1$ breast cancer & [63] \\
\hline$\beta-G a l$ & BOD-M- $\beta$ Gal & BODPY derivatives & $\begin{array}{c}\text { Hydrolyzation of } \\
\beta \text {-galactose residues }\end{array}$ & $808 / 900-1300$ & SKOV3 ovarian cancer & {$[72]$} \\
\hline MMP14 & $\begin{array}{l}\text { A\&MMP@Ag }{ }_{2} \mathrm{~S}- \\
\text { AF7P }\end{array}$ & $\mathrm{Ag}_{2} \mathrm{~S}$ & $\begin{array}{l}\text { Consumption of NIR } \\
\text { absorber A1094 }\end{array}$ & $785 / 1050$ & NB & {$[77]$} \\
\hline $\mathrm{H}_{2} \mathrm{O}_{2}$ & $\mathrm{Ag} / \mathrm{Ag}_{2} \mathrm{~S} \mathrm{JNP}$ & $\mathrm{Ag}_{2} \mathrm{~S}$ & $\begin{array}{l}\text { Oxidizing the plasmonic } \\
\text { Ag parts }\end{array}$ & $825 / 1250$ & MCF-7 breast cancer & [82] \\
\hline$\cdot \mathrm{OH}$ & Hydro-1080 & cyanine dyes & $\begin{array}{l}\text { Conjugated system } \\
\text { recovery }\end{array}$ & $980 / 1100$ & Liver injury & {$[88]$} \\
\hline $\mathrm{HClO}$ & SPNPs & PDF & $\begin{array}{l}\text { Degradation of the } \\
\text { receptor ITTC }\end{array}$ & $808 / 1010$ & Inflamed paws & [95] \\
\hline $\mathrm{ONOO}^{-}$ & $\mathrm{V \& A} @ \mathrm{Ag}_{2} \mathrm{~S}$ & $\mathrm{Ag}_{2} \mathrm{~S}$ & $\begin{array}{c}\text { Consumption of A1094 } \\
\text { chromophore }\end{array}$ & $825 / 1050$ & TBI & {$[105]$} \\
\hline $\mathrm{ONOO}^{-}$ & V\&C/PbS@Ag 2 Se & $\mathrm{PbS@Ag} \mathrm{Ae}_{2}$ & $\begin{array}{c}\text { Consumption of absorber } \\
\text { Cy7.5 }\end{array}$ & $808 / 1616$ & Ischemic stroke & [109] \\
\hline $\mathrm{NO}$ & AOSNP & $\mathrm{Ag}_{2} \mathrm{~S}$ & $\begin{array}{l}\text { Energy receptor units are } \\
\text { converted }\end{array}$ & $808 / 900-1150$ & Liver injury & [115] \\
\hline $\mathrm{H}_{2} \mathrm{~S}$ & WH-3 & BODIPY derivatives & $\begin{array}{c}\text { Release fluorescence } \\
\text { quencher }\end{array}$ & $980 / 1140$ & HCT-116 colon cancer & {$[121]$} \\
\hline Hypoxia (NTR) & IR-1048-MZ & IR-1048 & MZ group was reduced & $980 / 1046$ & A549 lung cancer & {$[126]$} \\
\hline Viscosity & $\mathrm{WD}-\mathrm{NO}_{2}$ & BODIPY derivatives & $\begin{array}{l}\text { Intramolecular rotation of } \\
\text { chemical bonds is limited }\end{array}$ & $808 / 900-1400$ & $\begin{array}{l}\text { Abnormal liver } \\
\text { viscosity }\end{array}$ & [131] \\
\hline Hyal and GSH & HISSNPs & IR-1061 & $\begin{array}{l}\text { Fracture of HA chains and } \\
\text { disulfide bonds }\end{array}$ & $808 / 1070$ & MCF-7 breast cancer & [139] \\
\hline
\end{tabular}

Although activatable NIR-II fluorescent probes have made encouraging progress, they still face some challenges, mainly reflected in the following. (1) False-positive results. This is mainly due to the limited difference in the concentration of biomarkers in diseased tissues and normal tissues, which may cause false-positive results in NIR-II fluorescence imaging. For example, NB highly expresses MMP; however, many normal cells also produce MMP. It is necessary to consider how to avoid false-positive results affecting the diagnosis of the disease. On the one hand, the probe can be activated in a dual-responsive manner, improving the specificity of imaging. On the other hand, the occurrence of falsepositive results is maximally avoided by setting the limit of detection. (2) Delivery of the fluorescent probe. The effective enrichment of the activatable NIR-II fluorescent probe in target tissues is the fundamental guarantee of successful biological imaging. Therefore, drug delivery systems, including liposomes and mesoporous organosilicons, are used to deliver fluorescent probes to the target tissue and improve their concentration in the target tissue. (3) Safety. Although the activatable NIR-II fluorescent probes need special conditions to be activated, fluorescent probes in normal tissues will have toxic and side effects. Moreover, nano fluorescent probes with larger particle sizes are not easily cleared in vivo, and long-term toxicity arises. Therefore, research on safety should be enhanced to provide guarantees for clinical applications.

In conclusion, activatable NIR-II fluorescent probes have undergone rapid development, which has effectively promoted research on fluorescence imaging. This review provides a reference for the design of, and research on, activatable NIR-II fluorescent probes and their applications in biological imaging. 
Author Contributions: Conceptualization, D.L. and G.L.; writing-original draft preparation, D.L. and J.P.; resources, S.X.; data curation, S.F.; project administration, D.L.; writing-review and editing, G.L. and C.C.; supervision, G.L. All authors have read and agreed to the published version of the manuscript.

Funding: This work was supported by the Major State Basic Research Development Program of China (2017YFA0205201), the National Natural Science Foundation of China (NSFC) (81925019, 81901876 and U1705281), the Fundamental Research Funds for the Central Universities (20720190088 and 20720200019), and the Program for New Century Excellent Talents in University, China (NCET-13-0502).

Institutional Review Board Statement: Not applicable.

Informed Consent Statement: Not applicable.

Data Availability Statement: Data are contained within the article.

Conflicts of Interest: The authors declare no conflict of interest.

\section{References}

1. Hong, G.; Antaris, A.L.; Dai, H. Near-infrared fluorophores for biomedical imaging. Nat. Biomed. Eng. 2017, 1, 1-22. [CrossRef]

2. Antaris, A.L.; Chen, H.; Cheng, K.; Sun, Y.; Hong, G.; Qu, C.; Diao, S.; Deng, Z.; Hu, X.; Zhang, B.; et al. A small-molecule dye for NIR-II imaging. Nat. Mater. 2016, 15, 235-242. [CrossRef] [PubMed]

3. Gao, X.; Cui, Y.; Levenson, R.M.; Chung, L.W.; Nie, S. In vivo cancer targeting and imaging with semiconductor quantum dots. Nat. Biotechnol. 2004, 22, 969-976. [CrossRef] [PubMed]

4. Smith, A.M.; Mancini, M.C.; Nie, S. Bioimaging: Second window for in vivo imaging. Nat. Nanotechnol. $2009,4,710-711$. [CrossRef]

5. Hong, G.; Zou, Y.; Antaris, A.L.; Diao, S.; Wu, D.; Cheng, K.; Zhang, X.; Chen, C.; Liu, B.; He, Y.; et al. Ultrafast fluorescence imaging in vivo with conjugated polymer fluorophores in the second near-infrared window. Nat. Commun. 2014, 5, 4206. [CrossRef]

6. Sheng, Z.; Guo, B.; Hu, D.; Xu, S.; Wu, W.; Liew, W.H.; Yao, K.; Jiang, J.; Liu, C.; Zheng, H.; et al. Bright aggregation-inducedemission dots for targeted synergetic NIR-II fluorescence and NIR-I photoacoustic imaging of orthotopic brain tumors. Adv. Mater. 2018, 30, 1800766. [CrossRef]

7. He, S.; Song, J.; Qu, J.; Cheng, Z. Crucial breakthrough of second near-infrared biological window fluorophores: Design and synthesis toward multimodal imaging and theranostics. Chem. Soc. Rev. 2018, 47, 4258-4278. [CrossRef]

8. Yang, Y.; Wang, S.; Lu, L.; Zhang, Q.; Yu, P.; Fan, Y.; Zhang, F. NIR-II chemiluminescence molecular sensor for in vivo high-contrast inflammation imaging. Angew. Chem. Int. Ed. 2020, 59, 18380-18385. [CrossRef]

9. Antaris, A.L.; Chen, H.; Diao, S.; Ma, Z.; Zhang, Z.; Zhu, S.; Wang, J.; Lozano, A.X.; Fan, Q.; Chew, L.; et al. A high quantum yield molecule-protein complex fluorophore for near-infrared II imaging. Nat. Commun. 2017, 8, 15269. [CrossRef]

10. Hu, Z.; Fang, C.; Li, B.; Zhang, Z.; Cao, C.; Cai, M.; Su, S.; Sun, X.; Shi, X.; Li, C.; et al. First-in-human liver-tumour surgery guided by multispectral fluorescence imaging in the visible and near-infrared-I/II windows. Nat. Biomed. Eng. 2020, 4, $259-271$. [CrossRef]

11. Yang, Q.; Hu, Z.; Zhu, S.; Ma, R.; Ma, H.; Ma, Z.; Wan, H.; Zhu, T.; Jiang, Z.; Liu, W.; et al. Donor engineering for NIR-II molecular fluorophores with enhanced fluorescent performance. J. Am. Chem. Soc. 2018, 140, 1715-1724. [CrossRef]

12. Lei, Z.; Zhang, F. Molecular engineering of NIR-II fluorophores for improved biomedical detection. Angew. Chem. Int. Ed. 2021, 60, 16294-16308. [CrossRef]

13. Huang, J.; Pu, K. Activatable molecular probes for second near-infrared fluorescence, chemiluminescence, and photoacoustic imaging. Angew. Chem. Int. Ed. 2020, 59, 11717-11731. [CrossRef]

14. Chen, C.; Tian, R.; Zeng, Y.; Chu, C.; Liu, G. Activatable fluorescence probes for "turn-on" and ratiometric biosensing and bioimaging: From NIR-I to NIR-II. Bioconjug. Chem. 2020, 31, 276-292. [CrossRef]

15. Zheng, H.; Ma, B.; Shi, Y.; Dai, Q.; Li, D.; Ren, E.; Zhu, J.; Liu, J.; Chen, H.; Yin, Z.; et al. Tumor microenvironment-triggered $\mathrm{MoS}_{2} @ G A-F e$ nanoreactor: A self-rolling enhanced chemodynamic therapy and hydrogen sulfide treatment for hepatocellular carcinoma. Chem. Eng. J. 2021, 406, 126888. [CrossRef]

16. Chu, C.; Yu, J.; Ren, E.; Ou, S.; Zhang, Y.; Wu, Y.; Wu, H.; Zhang, Y.; Zhu, J.; Dai, Q.; et al. Multimodal photoacoustic imaging-guided regression of corneal neovascularization: A non-invasive and safe strategy. Adv. Sci. 2020, 7, 2000346. [CrossRef]

17. Shi, X.; Zhang, Y.; Tian, Y.; Xu, S.; Ren, E.; Bai, S.; Chen, X.; Chu, C.; Xu, Z.; Liu, G. Multi-responsive bottlebrush-like unimolecules self-assembled nano-riceball for synergistic sono-chemotherapy. Small Methods 2020, 5, 2000416. [CrossRef]

18. He, T.; Jiang, C.; He, J.; Zhang, Y.; He, G.; Wu, J.; Lin, J.; Zhou, X.; Huang, P. Manganese-dioxide-coating-instructed plasmonic modulation of gold nanorods for activatable duplex-imaging-guided NIR-II photothermal-chemodynamic therapy. Adv. Mater. 2021, 33, 2008540. [CrossRef]

19. Feng, B.; Hou, B.; Xu, Z.; Saeed, M.; Yu, H.; Li, Y. Self-amplified drug delivery with light-inducible nanocargoes to enhance cancer immunotherapy. Adv. Mater. 2019, 31, 1902960. [CrossRef] 
20. Li, X.; Zheng, B.Y.; Ke, M.R.; Zhang, Y.; Huang, J.D.; Yoon, J. A tumor-pH-responsive supramolecular photosensitizer for activatable photodynamic therapy with minimal in vivo skin phototoxicity. Theranostics 2017, 7, 2746-2756. [CrossRef]

21. Li, D.; Wang, S.; Lei, Z.; Sun, C.; El-Toni, A.M.; Alhoshan, M.S.; Fan, Y.; Zhang, F. Peroxynitrite activatable NIR-II fluorescent molecular probe for drug-induced hepatotoxicity monitoring. Anal. Chem. 2019, 91, 4771-4779. [CrossRef]

22. Danko, M.; Hrdlovic, P.; Martinicka, A.; Benda, A.; Cigan, M. Spectral properties of ionic benzotristhiazole based donor-acceptor NLO-phores in polymer matrices and their one- and two-photon cellular imaging ability. Photochem. Photobiol. Sci. 2017, 16, 1832-1844. [CrossRef]

23. Zhou, C.; Zhang, L.; Sun, T.; Zhang, Y.; Liu, Y.; Gong, M.; Xu, Z.; Du, M.; Liu, Y.; Liu, G.; et al. Activatable NIR-II plasmonic nanotheranostics for efficient photoacoustic imaging and photothermal cancer therapy. Adv. Mater. 2021, 33, 2006532. [CrossRef]

24. Zhao, M.; Li, B.; Zhang, H.; Zhang, F. Activatable fluorescence sensors for in vivo bio-detection in the second near-infrared window. Chem. Sci. 2020, 12, 3448-3459. [CrossRef]

25. Zheng, B.D.; Ye, J.; Zhang, X.Q.; Zhang, N.; Xiao, M.T. Recent advances in supramolecular activatable phthalocyanine-based photosensitizers for anti-cancer therapy. Coord. Chem. Rev. 2021, 447, 214155. [CrossRef]

26. Li, X.; Kolemen, S.; Yoon, J.; Akkaya, E.U. Activatable photosensitizers: Agents for selective photodynamic therapy. Adv. Funct. Mater. 2017, 27, 1604053. [CrossRef]

27. Li, D.; Wang, X.Z.; Yang, L.F.; Li, S.C.; Hu, Q.Y.; Li, X.; Zheng, B.Y.; Ke, M.R.; Huang, J.D. Size-tunable targeting-triggered nanophotosensitizers based on self-assembly of a phthalocyanine-biotin conjugate for photodynamic therapy. ACS Appl. Mater. Interf. 2019, 11, 36435-36443. [CrossRef]

28. Li, X.; Yu, S.; Lee, Y.; Guo, T.; Kwon, N.; Lee, D.; Yeom, S.C.; Cho, Y.; Kim, G.; Huang, J.D.; et al. In vivo albumin traps photosensitizer monomers from self-assembled phthalocyanine nanovesicles: A facile and switchable theranostic approach. $J$. Am. Chem. Soc. 2019, 141, 1366-1372. [CrossRef]

29. Li, X.; Yu, S.; Lee, D.; Kim, G.; Lee, B.; Cho, Y.; Zheng, B.Y.; Ke, M.R.; Huang, J.D.; Nam, K.T.; et al. Facile supramolecular approach to nucleic-acid-driven activatable nanotheranostics that overcome drawbacks of photodynamic therapy. ACS Nano 2018, 12, 681-688. [CrossRef]

30. Ding, F.; Zhan, Y.; Lu, X.; Sun, Y. Recent advances in near-infrared II fluorophores for multifunctional biomedical imaging. Chem. Sci. 2018, 9, 4370-4380. [CrossRef]

31. Li, L.; Dong, X.; Li, J.; Wei, J. A short review on NIR-II organic small molecule dyes. Dyes Pigments 2020, 183, 108756. [CrossRef]

32. Zhou, H.; Xiao, Y.; Hong, X. New NIR-II dyes without a benzobisthiadiazole core. Chin. Chem. Lett. 2018, 29, 1425-1428. [CrossRef]

33. Zhou, H.; Yi, W.; Li, A.; Wang, B.; Ding, Q.; Xue, L.; Zeng, X.; Feng, Y.; Li, Q.; Wang, T.; et al. Specific small-molecule NIR-II fluorescence imaging of osteosarcoma and lung metastasis. Adv. Healthc. Mater. 2020, 9, 1901224. [CrossRef] [PubMed]

34. Qi, J.; Sun, C.; Zebibula, A.; Zhang, H.; Kwok, R.T.K.; Zhao, X.; Xi, W.; Lam, J.W.Y.; Qian, J.; Tang, B.Z. Real-time and highresolution bioimaging with bright aggregation-induced emission dots in short-wave infrared region. Adv. Mater. 2018, 30, 1706856. [CrossRef]

35. Samanta, S.; Huang, M.; Li, S.; Yang, Z.; He, Y.; Gu, Z.; Zhang, J.; Zhang, D.; Liu, L.; Qu, J. AIE-active two-photon fluorescent nanoprobe with NIR-II light excitability for highly efficient deep brain vasculature imaging. Theranostics 2021, 11, 2137-2148. [CrossRef]

36. Li, B.; Lu, L.; Zhao, M.; Lei, Z.; Zhang, F. An efficient 1064 nm NIR-II excitation fluorescent molecular dye for deep-tissue high-resolution dynamic bioimaging. Angew. Chem. Int. Ed. 2018, 57, 7483-7487. [CrossRef]

37. Bai, L.; Sun, P.; Liu, Y.; Zhang, H.; Hu, W.; Zhang, W.; Liu, Z.; Fan, Q.; Li, L.; Huang, W. Novel aza-BODIPY based small molecular NIR-II fluorophores for in vivo imaging. Chem. Commun. 2019, 55, 10920-10923. [CrossRef]

38. Rathnamalala, C.S.L.; Gayton, J.N.; Dorris, A.L.; Autry, S.A.; Meador, W.; Hammer, N.I.; Delcamp, J.H.; Scott, C.N. Donor-acceptordonor NIR II emissive rhodindolizine dye synthesized by C-H bond functionalization. J. Org. Chem. 2019, 84, 13186-13193. [CrossRef]

39. Zeng, X.; Xue, L.; Chen, D.; Li, S.; Nong, J.; Wang, B.; Tang, L.; Li, Q.; Li, Y.; Deng, Z.; et al. A bright NIR-II fluorescent probe for breast carcinoma imaging and image-guided surgery. Chem. Commun. 2019, 55, 14287-14290. [CrossRef]

40. Yang, R.Q.; Lou, K.L.; Wang, P.Y.; Gao, Y.Y.; Zhang, Y.Q.; Chen, M.; Huang, W.H.; Zhang, G.J. Surgical navigation for malignancies guided by near-infrared-II fluorescence imaging. Small Methods 2021, 5, 2001066. [CrossRef]

41. Yang, F.; Zhang, Q.; Huang, S.; Ma, D. Recent advances of near infrared inorganic fluorescent probes for biomedical applications. J. Mater. Chem. B 2020, 8, 7856-7879. [CrossRef]

42. Zhu, S.; Tian, R.; Antaris, A.L.; Chen, X.; Dai, H. Near-infrared-II molecular dyes for cancer imaging and surgery. Adv. Mater. 2019, 31, 1900321. [CrossRef]

43. Li, C.; Zhang, Y.; Wang, M.; Zhang, Y.; Chen, G.; Li, L.; Wu, D.; Wang, Q. In vivo real-time visualization of tissue blood flow and angiogenesis using $\mathrm{Ag}_{2} \mathrm{~S}$ quantum dots in the NIR-II window. Biomaterials 2014, 35, 393-400. [CrossRef]

44. Takeuchi, T.; Iizumi, Y.; Yudasaka, M.; Kizaka-Kondoh, S.; Okazaki, T. Characterization and biodistribution analysis of oxygendoped single-walled carbon nanotubes used as in vivo fluorescence imaging probes. Bioconjug. Chem. 2019, 30, 1323-1330. [CrossRef] 
45. Ghosh, D.; Bagley, A.F.; Na, Y.J.; Birrer, M.J.; Bhatia, S.N.; Belcher, A.M. Deep, noninvasive imaging and surgical guidance of submillimeter tumors using targeted M13-stabilized single-walled carbon nanotubes. Proc. Natl. Acad. Sci. USA 2014, 111, 13948-13953. [CrossRef]

46. Lei, X.; Li, R.; Tu, D.; Shang, X.; Liu, Y.; You, W.; Sun, C.; Zhang, F.; Chen, X. Intense near-infrared-II luminescence from $\mathrm{NaCeF} 4 \mathrm{Er} / \mathrm{Yb}$ nanoprobes for in vitro bioassay and in vivo bioimaging. Chem. Sci. 2018, 9, 4682-4688. [CrossRef]

47. Xue, Z.; Zeng, S.; Hao, J. Non-invasive through-skull brain vascular imaging and small tumor diagnosis based on NIR-II emissive lanthanide nanoprobes beyond 1500nm. Biomaterials 2018, 171, 153-163. [CrossRef]

48. Su, M.; Dai, Q.; Chen, C.; Zeng, Y.; Chu, C.; Liu, G. Nano-medicine for thrombosis: A precise diagnosis and treatment strategy. Nano-Micro Lett. 2020, 12, 96. [CrossRef]

49. Ke, M.R.; Chen, S.F.; Peng, X.H.; Zheng, Q.F.; Zheng, B.Y.; Yeh, C.K.; Huang, J.D. A tumor-targeted activatable phthalocyaninetetrapeptide-doxorubicin conjugate for synergistic chemo-photodynamic therapy. Eur. J. Med. Chem. 2017, 127, 200-209. [CrossRef]

50. Zhou, K.; Liu, H.; Zhang, S.; Huang, X.; Wang, Y.; Huang, G.; Sumer, B.D.; Gao, J. Multicolored pH-tunable and activatable fluorescence nanoplatform responsive to physiologic $\mathrm{pH}$ stimuli. J. Am. Chem. Soc. 2012, 134, 7803-7811. [CrossRef]

51. Yue, Y.; Huo, F.; Lee, S.; Yin, C.; Yoon, J. A review: The trend of progress about $\mathrm{pH}$ probes in cell application in recent years. Analyst 2017, 142, 30-41. [CrossRef] [PubMed]

52. Gong, F.; Yang, N.; Wang, X.; Zhao, Q.; Chen, Q.; Liu, Z.; Cheng, L. Tumor microenvironment-responsive intelligent nanoplatforms for cancer theranostics. Nano Today 2020, 32, 100851. [CrossRef]

53. Raish, M.; Shahid, M.; Bin Jardan, Y.A.; Ansari, M.A.; Alkharfy, K.M.; Ahad, A.; Abdelrahman, I.A.; Ahmad, A.; Al-Jenoobi, F.I. Gastroprotective effect of sinapic acid on ethanol-induced gastric ulcers in rats: Involvement of Nrf2/HO-1 and NF-kappaB signaling and antiapoptotic role. Front. Pharmacol. 2021, 12, 622815. [CrossRef] [PubMed]

54. Wang, S.; Fan, Y.; Li, D.; Sun, C.; Lei, Z.; Lu, L.; Wang, T.; Zhang, F. Anti-quenching NIR-II molecular fluorophores for in vivo high-contrast imaging and $\mathrm{pH}$ sensing. Nat. Commun. 2019, 10, 1058. [CrossRef] [PubMed]

55. Zhao, M.; Wang, J.; Lei, Z.; Lu, L.; Wang, S.; Zhang, H.; Li, B.; Zhang, F. NIR-II pH sensor with a FRET adjustable transition point for in situ dynamic tumor microenvironment visualization. Angew. Chem. Int. Ed. 2021, 60, 5091-5095. [CrossRef]

56. Wu, J.; You, L.; Chaudhry, S.T.; He, J.; Cheng, J.X.; Mei, J. Ambient oxygen-doped conjugated polymer for pH-activatable aggregation-enhanced photoacoustic imaging in the second near-infrared window. Anal. Chem. 2021, 93, 3189-3195. [CrossRef]

57. Ren, E.; Chu, C.; Zhang, Y.; Wang, J.; Pang, X.; Lin, X.; Liu, C.; Shi, X.; Dai, Q.; Lv, P.; et al. Mimovirus vesicle-based biological orthogonal reaction for cancer diagnosis. Small Methods 2020, 4, 2000291. [CrossRef]

58. Li, J.; Zheng, L.; Li, C.; Xiao, Y.; Liu, J.; Wu, S.; Zhang, B. Mannose modified zwitterionic polyester-conjugated second near-infrared organic fluorophore for targeted photothermal therapy. Biomater. Sci. 2021, 9, 4648-4661. [CrossRef]

59. Bai, S.; Zhang, Y.; Li, D.; Shi, X.; Lin, G.; Liu, G. Gain an advantage from both sides: Smart size-shrinkable drug delivery nanosystems for high accumulation and deep penetration. Nano Today 2021, 36, 101038. [CrossRef]

60. Wang, X.; Li, C.; Qian, J.; Lv, X.; Li, H.; Zou, J.; Zhang, J.; Meng, X.; Liu, H.; Qian, Y.; et al. NIR-II responsive hollow magnetite nanoclusters for targeted magnetic resonance imaging-guided photothermal/chemo-therapy and chemodynamic therapy. Small 2021, 17, 2100794. [CrossRef]

61. Zhao, P.H.; Ma, S.T.; Hu, J.Q.; Zheng, B.Y.; Ke, M.R.; Huang, J.D. Artesunate-based multifunctional nanoplatform for photother$\mathrm{mal} /$ photoinduced thermodynamic synergistic anticancer therapy. ACS Appl. Bio. Mater. 2020, 3, 7876-7885. [CrossRef]

62. Ling, S.; Yang, X.; Li, C.; Zhang, Y.; Yang, H.; Chen, G.; Wang, Q. Tumor microenvironment-activated NIR-II nanotheranostic system for precise diagnosis and treatment of peritoneal metastasis. Angew. Chem. Int. Ed. 2020, 59, 7219-7223. [CrossRef]

63. Liu, T.; Zhang, X.; Liu, D.; Chen, B.; Ge, X.; Gao, S.; Song, J. Self-assembled $\mathrm{Ag}_{2} \mathrm{~S}-\mathrm{QD}$ vesicles for in situ responsive NIR-II fluorescence imaging-guided photothermal cancer therapy. Adv. Optl. Mater. 2021, 9, 2100233. [CrossRef]

64. Zhang, Y.; Wang, X.; Chu, C.; Zhou, Z.; Chen, B.; Pang, X.; Lin, G.; Lin, H.; Guo, Y.; Ren, E.; et al. Genetically engineered magnetic nanocages for cancer magneto-catalytic theranostics. Nat. Commun. 2020, 11, 5421. [CrossRef]

65. Shi, Y.; Wang, J.; Liu, J.; Lin, G.; Xie, F.; Pang, X.; Pei, Y.; Cheng, Y.; Zhang, Y.; Lin, Z.; et al. Oxidative stress-driven DR5 upregulation restores TRAIL/Apo2L sensitivity induced by iron oxide nanoparticles in colorectal cancer. Biomaterials 2020, 233, 119753. [CrossRef]

66. Gong, L.; Shan, X.; Zhao, X.H.; Tang, L.; Zhang, X.B. Activatable NIR-II fluorescent probes applied in biomedicine: Progress and perspectives. ChemMedChem 2021, 16, 2426-2440. [CrossRef]

67. Suzuki, H.; Ohto, U.; Higaki, K.; Mena-Barragan, T.; Aguilar-Moncayo, M.; Ortiz Mellet, C.; Nanba, E.; Garcia Fernandez, J.M.; Suzuki, Y.; Shimizu, T. Structural basis of pharmacological chaperoning for human beta-galactosidase. J. Biol. Chem. 2014, 289, 14560-14568. [CrossRef]

68. Ohto, U.; Usui, K.; Ochi, T.; Yuki, K.; Satow, Y.; Shimizu, T. Crystal structure of human beta-galactosidase: Structural basis of Gm1 gangliosidosis and morquio B diseases. J. Biol. Chem. 2012, 287, 1801-1812. [CrossRef]

69. Asanuma, D.; Sakabe, M.; Kamiya, M.; Yamamoto, K.; Hiratake, J.; Ogawa, M.; Kosaka, N.; Choyke, P.L.; Nagano, T.; Kobayashi, H.; et al. Sensitive beta-galactosidase-targeting fluorescence probe for visualizing small peritoneal metastatic tumours in vivo. Nat. Commun. 2015, 6, 6463. [CrossRef]

70. Kim, E.J.; Kumar, R.; Sharma, A.; Yoon, B.; Kim, H.M.; Lee, H.; Hong, K.S.; Kim, J.S. In vivo imaging of beta-galactosidase stimulated activity in hepatocellular carcinoma using ligand-targeted fluorescent probe. Biomaterials 2017, 122, 83-90. [CrossRef] 
71. Zhen, X.; Zhang, J.; Huang, J.; Xie, C.; Miao, Q.; Pu, K. Macrotheranostic probe with disease-activated near-infrared fluorescence, photoacoustic, and photothermal signals for imaging-guided therapy. Angew. Chem. Int. Ed. 2018, 57, 7804-7808. [CrossRef] [PubMed]

72. Chen, J.A.; Pan, H.; Wang, Z.; Gao, J.; Tan, J.; Ouyang, Z.; Guo, W.; Gu, X. Imaging of ovarian cancers using enzyme activatable probes with second near-infrared window emission. Chem. Commun. 2020, 56, 2731-2734. [CrossRef] [PubMed]

73. Gimeno, A.Z.; Santana, A.; Jimenez, A.; Parra, A.D.; Nicolas, D.; Paz, C.; Diaz, F.; Medina, C.; Diaz, L.; Quintero, E. Up-regulation of gelatinases in the colorectal adenoma-carcinoma sequence. Eur. J. Cancer 2006, 42, 3246-3252. [CrossRef] [PubMed]

74. Xiang, X.; Zhao, X.; Qu, H.; Li, D.; Yang, D.; Pu, J.; Mei, H.; Zhao, J.; Huang, K.; Zheng, L.; et al. Hepatocyte nuclear factor 4 alpha promotes the invasion, metastasis and angiogenesis of neuroblastoma cells via targeting matrix metalloproteinase 14. Cancer Lett. 2015, 359, 187-197. [CrossRef] [PubMed]

75. Esposito, M.R.; Binatti, A.; Pantile, M.; Coppe, A.; Mazzocco, K.; Longo, L.; Capasso, M.; Lasorsa, V.A.; Luksch, R.; Bortoluzzi, S.; et al. Somatic mutations in specific and connected subpathways are associated with short neuroblastoma patients' survival and indicate proteins targetable at onset of disease. Int. J. Cancer 2018, 143, 2525-2536. [CrossRef] [PubMed]

76. Jeong, S.; Song, J.; Lee, W.; Ryu, Y.M.; Jung, Y.; Kim, S.Y.; Kim, K.; Hong, S.C.; Myung, S.J.; Kim, S. Cancer-microenvironmentsensitive activatable quantum dot probe in the second near-infrared window. Nano Lett. 2017, 17, 1378-1386. [CrossRef]

77. Zhan, Y.; Ling, S.; Huang, H.; Zhang, Y.; Chen, G.; Huang, S.; Li, C.; Guo, W.; Wang, Q. Rapid unperturbed-tissue analysis for intraoperative cancer diagnosis using an enzyme-activated NIR-II nanoprobe. Angew. Chem. Int. Ed. 2021, 60, 2637-2642. [CrossRef]

78. Li, D.; Hu, Q.Y.; Wang, X.Z.; Li, X.; Hu, J.Q.; Zheng, B.Y.; Ke, M.R.; Huang, J.D. A non-aggregated silicon(IV) phthalocyaninelactose conjugate for photodynamic therapy. Bioorg. Med. Chem. Lett. 2020, 30, 127164. [CrossRef]

79. Zhao, Y.Y.; Chen, J.Y.; Hu, J.Q.; Zhang, L.; Lin, A.L.; Wang, R.; Zheng, B.Y.; Ke, M.R.; Li, X.; Huang, J.D. The substituted zinc(II) phthalocyanines using "sulfur bridge" as the linkages. synthesis, red-shifted spectroscopic properties and structure-inherent targeted photodynamic activities. Dyes Pigments 2021, 189, 109270. [CrossRef]

80. He, X.J.; Chen, H.; Xu, C.C.; Fan, J.Y.; Xu, W.; Li, Y.H.; Deng, H.; Shen, J.L. Ratiometric and colorimetric fluorescent probe for hypochlorite monitor and application for bioimaging in living cells, bacteria and zebrafish. J. Hazard. Mater. 2020, $388,122029$. [CrossRef]

81. Ye, J.; Li, Z.; Fu, Q.; Li, Q.; Zhang, X.; Su, L.; Yang, H.; Song, J. Quantitative photoacoustic diagnosis and precise treatment of inflammation in vivo using activatable theranostic nanoprobe. Adv. Funct. Mater. 2020, 30, 2001771. [CrossRef]

82. Zhang, X.; Wang, W.; Su, L.; Ge, X.; Ye, J.; Zhao, C.; He, Y.; Yang, H.; Song, J.; Duan, H. Plasmonic-fluorescent janus Ag/ Ag 2 S nanoparticles for in situ $\mathrm{H}_{2} \mathrm{O}_{2}$-activated NIR-II fluorescence imaging. Nano Lett. 2021, 21, 2625-2633. [CrossRef]

83. Khojah, H.M.; Ahmed, S.; Abdel-Rahman, M.S.; Hamza, A.B. Reactive oxygen and nitrogen species in patients with rheumatoid arthritis as potential biomarkers for disease activity and the role of antioxidants. Free Radic. Biol. Med. 2016, 97, 285-291. [CrossRef]

84. Sayre, L.M.; Perry, G.; Smith, M.A. Oxidative stress and neurotoxicity. Chem. Res. Toxicol. 2008, 21, 172-188. [CrossRef]

85. Wang, X.; Li, P.; Ding, Q.; Wu, C.; Zhang, W.; Tang, B. Observation of acetylcholinesterase in stress-induced depression phenotypes by two-photon fluorescence imaging in the mouse brain. J. Am. Chem. Soc. 2019, 141, 2061-2068. [CrossRef]

86. Oka, T.; Yamashita, S.; Midorikawa, M.; Saiki, S.; Muroya, Y.; Kamibayashi, M.; Yamashita, M.; Anzai, K.; Katsumura, Y. Spin-trapping reactions of a novel gauchetype radical trapper G-CYPMPO. Anal. Chem. 2011, 83, 9600-9604. [CrossRef]

87. Sun, W.; Guo, S.; Hu, C.; Fan, J.; Peng, X. Recent development of chemosensors based on cyanine platforms. Chem. Rev. 2016, 116, 7768-7817. [CrossRef]

88. Feng, W.; Zhang, Y.; Li, Z.; Zhai, S.; Lv, W.; Liu, Z. Lighting up NIR-II fluorescence in vivo: An activable probe for noninvasive hydroxyl radical imaging. Anal. Chem. 2019, 91, 15757-15762. [CrossRef]

89. Zhu, H.; Fan, J.; Wang, J.; Mu, H.; Peng, X. An "enhanced PET"-based fluorescent probe with ultrasensitivity for imaging basal and elesclomol-induced $\mathrm{HClO}$ in cancer cells. J. Am. Chem. Soc. 2014, 136, 12820-12823. [CrossRef]

90. Wu, L.; Wu, I.C.; DuFort, C.C.; Carlson, M.A.; Wu, X.; Chen, L.; Kuo, C.T.; Qin, Y.; Yu, J.; Hingorani, S.R.; et al. Photostable ratiometric pdot probe for in vitro and in vivo imaging of hypochlorous acid. J. Am. Chem. Soc. 2017, 139, 6911-6918. [CrossRef]

91. Li, J.; Rao, J.; Pu, K. Recent progress on semiconducting polymer nanoparticles for molecular imaging and cancer phototherapy. Biomaterials 2018, 155, 217-235. [CrossRef]

92. Wang, S.; Liu, L.; Fan, Y.; El-Toni, A.M.; Alhoshan, M.S.; Li, D.; Zhang, F. In vivo high-resolution ratiometric fluorescence imaging of inflammation using NIR-II nanoprobes with $1550 \mathrm{~nm}$ emission. Nano Lett. 2019, 19, 2418-2427. [CrossRef]

93. Miao, Q.; Xie, C.; Zhen, X.; Lyu, Y.; Duan, H.; Liu, X.; Jokerst, J.V.; Pu, K. Molecular afterglow imaging with bright, biodegradable polymer nanoparticles. Nat. Biotechnol. 2017, 35, 1102-1110. [CrossRef]

94. Ge, X.; Lou, Y.; Su, L.; Chen, B.; Guo, Z.; Gao, S.; Zhang, W.; Chen, T.; Song, J.; Yang, H. Single wavelength laser excitation ratiometric NIR-II fluorescent probe for molecule imaging in vivo. Anal. Chem. 2020, 92, 6111-6120. [CrossRef]

95. Tang, Y.; Li, Y.; Lu, X.; Hu, X.; Zhao, H.; Hu, W.; Lu, F.; Fan, Q.; Huang, W. Bio-erasable intermolecular donor-acceptor interaction of organic semiconducting nanoprobes for activatable NIR-II fluorescence imaging. Adv. Funct. Mater. 2019, $29,1807376$. [CrossRef]

96. Kwon, N.; Kim, D.; Swamy, K.M.K.; Yoon, J. Metal-coordinated fluorescent and luminescent probes for reactive oxygen species (ROS) and reactive nitrogen species (RNS). Coord. Chem. Rev. 2021, 427, 213581. [CrossRef] 
97. Tang, Y.; Pei, F.; Lu, X.; Fan, Q.; Huang, W. Recent advances on activatable NIR-II fluorescence probes for biomedical imaging. Adv. Opt. Mater. 2019, 7, 1900917. [CrossRef]

98. Szabo, C.; Ischiropoulos, H.; Radi, R. Peroxynitrite: Biochemistry, pathophysiology and development of therapeutics. Nat. Rev. Drug Discov. 2007, 6, 662-680. [CrossRef]

99. Ai, X.; Wang, Z.; Cheong, H.; Wang, Y.; Zhang, R.; Lin, J.; Zheng, Y.; Gao, M.; Xing, B. Multispectral optoacoustic imaging of dynamic redox correlation and pathophysiological progression utilizing upconversion nanoprobes. Nat. Commun. 2019, 10, 1087. [CrossRef]

100. Zhao, M.; Li, B.; Wu, Y.; He, H.; Zhu, X.; Zhang, H.; Dou, C.; Feng, L.; Fan, Y.; Zhang, F. A tumor-microenvironment-responsive lanthanide-cyanine FRET sensor for NIR-II luminescence-lifetime in situ imaging of hepatocellular carcinoma. Adv. Mater. 2020, 32, 2001172. [CrossRef]

101. Zhang, J.; Zhen, X.; Upputuri, P.K.; Pramanik, M.; Chen, P.; Pu, K. Activatable photoacoustic nanoprobes for in vivo ratiometric imaging of peroxynitrite. Adv. Mater. 2017, 29, 1604764. [CrossRef] [PubMed]

102. Uteshev, V.V. Allosteric modulation of nicotinic acetylcholine receptors: The concept and therapeutic trends. Curr. Pharm. Des. 2016, 22, 1986-1997. [CrossRef] [PubMed]

103. Li, X.; Tao, R.R.; Hong, L.J.; Cheng, J.; Jiang, Q.; Lu, Y.M.; Liao, M.H.; Ye, W.F.; Lu, N.N.; Han, F.; et al. Visualizing peroxynitrite fluxes in endothelial cells reveals the dynamic progression of brain vascular injury. J. Am. Chem. Soc. 2015, 137, 12296-12303. [CrossRef] [PubMed]

104. Adibhatla, R.M.; Hatcher, J.F. Lipid oxidation and peroxidation in CNS health and disease: From molecular mechanisms to therapeutic opportunities. Antioxid. Redox Signal. 2010, 12, 125-169. [CrossRef]

105. Li, C.; Li, W.; Liu, H.; Zhang, Y.; Chen, G.; Li, Z.; Wang, Q. An activatable NIR-II nanoprobe for in vivo early real-time diagnosis of traumatic brain injury. Angew. Chem. Int. Ed. 2020, 59, 247-252. [CrossRef]

106. Zhang, K.; Tu, M.; Gao, W.; Cai, X.; Song, F.; Chen, Z.; Zhang, Q.; Wang, J.; Jin, C.; Shi, J.; et al. Hollow prussian blue nanozymes drive neuroprotection against ischemic stroke via attenuating oxidative stress, counteracting inflammation, and suppressing cell apoptosis. Nano Lett. 2019, 19, 2812-2823. [CrossRef]

107. Li, S.; Jiang, D.; Ehlerding, E.B.; Rosenkrans, Z.T.; Engle, J.W.; Wang, Y.; Liu, H.; Ni, D.; Cai, W. Intrathecal administration of nanoclusters for protecting neurons against oxidative stress in cerebral ischemia/reperfusion injury. ACS Nano 2019, 13, 13382-13389. [CrossRef]

108. Liu, Y.; Ai, K.; Ji, X.; Askhatova, D.; Du, R.; Lu, L.; Shi, J. Comprehensive insights into the multi-antioxidative mechanisms of melanin nanoparticles and their application to protect brain from injury in ischemic stroke. J. Am. Chem. Soc. 2017, 139, 856-862. [CrossRef]

109. Yang, X.; Wang, Z.; Huang, H.; Ling, S.; Zhang, R.; Zhang, Y.; Chen, G.; Li, C.; Wang, Q. A targeted activatable NIR-IIb nanoprobe for highly sensitive detection of ischemic stroke in a photothrombotic stroke model. Adv. Healthc. Mater. 2021, 10, 2001544. [CrossRef]

110. Wang, R.; Zhou, L.; Wang, W.; Li, X.; Zhang, F. In vivo gastrointestinal drug-release monitoring through second near-infrared window fluorescent bioimaging with orally delivered microcarriers. Nat. Commun. 2017, 8, 14702. [CrossRef]

111. Xie, C.; Zhen, X.; Lyu, Y.; Pu, K. Nanoparticle regrowth enhances photoacoustic signals of semiconducting macromolecular probe for in vivo imaging. Adv. Mater. 2017, 29, 1703693. [CrossRef]

112. Peng, J.; Samanta, A.; Zeng, X.; Han, S.; Wang, L.; Su, D.; Loong, D.T.; Kang, N.Y.; Park, S.J.; All, A.H.; et al. Real-time in vivo hepatotoxicity monitoring through chromophore-conjugated photon-upconverting nanoprobes. Angew. Chem. Int. Ed. 2017, 56, 4165-4169. [CrossRef]

113. Shuhendler, A.J.; Pu, K.; Cui, L.; Uetrecht, J.P.; Rao, J. Real-time imaging of oxidative and nitrosative stress in the liver of live animals for drug-toxicity testing. Nat. Biotechnol. 2014, 32, 373380. [CrossRef]

114. Iverson, N.M.; Barone, P.W.; Shandell, M.; Trudel, L.J.; Sen, S.; Sen, F.; Ivanov, V.; Atolia, E.; Farias, E.; McNicholas, T.P.; et al. In vivo biosensing via tissue-localizable near-infrared-fluorescent single-walled carbon nanotubes. Nat. Nanotechnol. 2013, 8, 873-880. [CrossRef]

115. Tang, Y.; Li, Y.; Wang, Z.; Pei, F.; Hu, X.; Ji, Y.; Li, X.; Zhao, H.; Hu, W.; Lu, X.; et al. Organic semiconducting nanoprobe with redox-activatable NIR-II fluorescence for in vivo real-time monitoring of drug toxicity. Chem. Commun. 2019, 55, 27-30. [CrossRef]

116. Shi, B.; Yan, Q.; Tang, J.; Xin, K.; Zhang, J.; Zhu, Y.; Xu, G.; Wang, R.; Chen, J.; Gao, W.; et al. Hydrogen sulfide-activatable second near-infrared fluorescent nanoassemblies for targeted photothermal cancer therapy. Nano Lett. 2018, 18, 6411-6416. [CrossRef]

117. Xu, G.; Yan, Q.; Lv, X.; Zhu, Y.; Xin, K.; Shi, B.; Wang, R.; Chen, J.; Gao, W.; Shi, P.; et al. Imaging of colorectal cancers using activatable nanoprobes with second near-infrared window emission. Angew. Chem. Int. Ed. 2018, 57, 3626-3630. [CrossRef]

118. Bai, S.; Jia, D.; Ma, X.; Liang, M.; Xue, P.; Kang, Y.; Xu, Z. Cylindrical polymer brushes-anisotropic unimolecular micelle drug delivery system for enhancing the effectiveness of chemotherapy. Bioact. Mater. 2021, 6, 2894-2904. [CrossRef]

119. Li, Z.; Wu, J.; Wang, Q.; Liang, T.; Ge, J.; Wang, P.; Liu, Z. A universal strategy to construct lanthanide-doped nanoparticles-based activable NIR-II luminescence probe for bioimaging. iScience 2020, 23, 100962. [CrossRef]

120. Yang, Z.; Luo, Y.; Hu, Y.; Liang, K.; He, G.; Chen, Q.; Wang, Q.; Chen, H. Photothermo-promoted nanocatalysis combined with $\mathrm{H}_{2} \mathrm{~S}$-mediated respiration inhibition for efficient cancer therapy. Adv. Funct. Mater. 2021, 31, 2007991. [CrossRef]

121. Dou, K.; Feng, W.; Fan, C.; Cao, Y.; Xiang, Y.; Liu, Z. Flexible designing strategy to construct activatable NIR-II fluorescent probes with emission maxima beyond $1200 \mathrm{~nm}$. Anal. Chem. 2021, 93, 4006-4014. [CrossRef] 
122. Liu, Q.; Zhong, Y.; Su, Y.; Zhao, L.; Peng, J. Real-time imaging of hepatic inflammation using hydrogen sulfide-activatable second near-infrared luminescent nanoprobes. Nano Lett. 2021, 21, 4606-4614. [CrossRef]

123. Xu, M.; Wang, P.; Sun, S.; Gao, L.; Sun, L.; Zhang, L.; Zhang, J.; Wang, S.; Liang, X. Smart strategies to overcome tumor hypoxia toward the enhancement of cancer therapy. Nanoscale 2020, 12, 21519-21533. [CrossRef]

124. Brown, J.M.; Wilson, W.R. Exploiting tumour hypoxia in cancer treatment. Nat. Rev. Cancer 2004, 4, 437-447. [CrossRef] [PubMed]

125. Sundaram, A.; Peng, L.; Chai, L.; Xie, Z.; Ponraj, J.S.; Wang, X.; Wang, G.; Zhang, B.; Nie, G.; Xie, N.; et al. Advanced nanomaterials for hypoxia tumor therapy: Challenges and solutions. Nanoscale 2020, 12, 21497-21518. [CrossRef] [PubMed]

126. Meng, X.; Zhang, J.; Sun, Z.; Zhou, L.; Deng, G.; Li, S.; Li, W.; Gong, P.; Cai, L. Hypoxia-triggered single molecule probe for high-contrast NIR II/PA tumor imaging and robust photothermal therapy. Theranostics 2018, 8, 6025-6034. [CrossRef] [PubMed]

127. Qiu, G.Z.; Jin, M.Z.; Dai, J.X.; Sun, W.; Feng, J.H.; Jin, W.L. Reprogramming of the tumor in the hypoxic niche: The emerging concept and associated therapeutic strategies. Trends Pharmacol. Sci. 2017, 38, 669-686. [CrossRef] [PubMed]

128. Wallace, D.C. Mitochondria and cancer. Nat. Rev. Cancer 2012, 12, 685-698. [CrossRef]

129. Yang, Z.; He, Y.; Lee, J.H.; Park, N.; Suh, M.; Chae, W.S.; Cao, J.; Peng, X.; Jung, H.; Kang, C.; et al. A self-calibrating bipartite viscosity sensor for mitochondria. J. Am. Chem. Soc. 2013, 135, 9181-9185. [CrossRef]

130. Liu, F.; Yuan, Z.; Sui, X.; Wang, C.; Xu, M.; Li, W.; Chen, Y. Viscosity sensitive near-infrared fluorescent probes based on functionalized single-walled carbon nanotubes. Chem. Commun. 2020, 56, 8301-8304. [CrossRef]

131. Dou, K.; Huang, W.; Xiang, Y.; Li, S.; Liu, Z. Design of activatable NIR-II molecular probe for in vivo elucidation of disease-related viscosity variations. Anal. Chem. 2020, 92, 4177-4181. [CrossRef]

132. Kwon, H.; Kim, M.; Meany, B.; Piao, Y.; Powell, L.R.; Wang, Y. Optical probing of local pH and temperature in complex fluids with covalently functionalized, semiconducting carbon nanotubes. J. Phys. Chem. C 2015, 119, 3733-3739. [CrossRef]

133. Lau, J.T.; Lo, P.C.; Jiang, X.J.; Wang, Q.; Ng, D.K. A dual activatable photosensitizer toward targeted photodynamic therapy. J. Med. Chem. 2014, 57, 4088-4097. [CrossRef]

134. Zheng, Z.; Chen, Q.; Dai, R.; Jia, Z.; Yang, C.; Peng, X.; Zhang, R. A continuous stimuli-responsive system for NIR-II fluorescence/photoacoustic imaging guided photothermal/gas synergistic therapy. Nanoscale 2020, 12, 11562-11572. [CrossRef]

135. Xu, Q.; Lee, K.A.; Lee, S.; Lee, K.M.; Lee, W.J.; Yoon, J. A highly specific fluorescent probe for hypochlorous acid and its application in imaging microbe-induced HOCl production. J. Am. Chem. Soc. 2013, 135, 9944-9949. [CrossRef]

136. He, Y.; Wang, S.; Yu, P.; Yan, K.; Ming, J.; Yao, C.; He, Z.; El-Toni, A.M.; Khan, A.; Zhu, X.; et al. NIR-II cell endocytosis-activated fluorescent probes for in vivo high-contrast bioimaging diagnostics. Chem. Sci. 2021, 12, 10474-10482. [CrossRef]

137. Teng, L.; Song, G.; Liu, Y.; Han, X.; Li, Z.; Wang, Y.; Huan, S.; Zhang, X.B.; Tan, W. Nitric oxide-activated "dual-key-one-lock" nanoprobe for in vivo molecular imaging and high-specificity cancer therapy. J. Am. Chem. Soc. 2019, 141, 13572-13581. [CrossRef]

138. Teng, K.X.; Niu, L.Y.; Kang, Y.F.; Yang, Q.Z. Rational design of a "dual lock-and-key" supramolecular photosensitizer based on aromatic nucleophilic substitution for specific and enhanced photodynamic therapy. Chem. Sci. 2020, 11, 9703-9711. [CrossRef]

139. Tang, Y.; Li, Y.; Hu, X.; Zhao, H.; Ji, Y.; Chen, L.; Hu, W.; Zhang, W.; Li, X.; Lu, X.; et al. “Dual lock-and-key"-controlled nanoprobes for ultrahigh specific fluorescence imaging in the second near-infrared window. Adv. Mater. 2018, 30, 1801140. [CrossRef] 